\title{
HUMAN MEIOSIS I. THE HUMAN PACHYTENE KARYOTYPE ANALYZED BY THREE DIMENSIONAL RECONSTRUCTION OF THE SYNAPTONEMAL COMPLEX
}

\author{
by \\ PREBEN BACH HOLM \\ and \\ SøREN WILKEN RASMUSSEN \\ Department of Physiology, Carlsberg Laboratory \\ Gamle Carlsberg Vej 10, DK-2500 Copenhagen, Valby
}

Key words: Human spermatocytes, ultrastructure, XY body, nucleolus, centromeric heteromatin

The synaptonemal complexes of the 22 autosomal bivalents have been reconstructed in 22 human spermatocyte nuclei at pachytene. The mean total length of the autosomal synaptonemal complexes has been measured and amounts to $231 \mu \mathrm{m}($ s.d. $=16 \mu \mathrm{m})$. On the basis of absolute and relative lengths and the position of the centromeric heterochromatin it was possible to identify 14 of the 22 autosomal bivalents and to allocate each of the remaining 8 bivalents unequivocally to a major group. The relative synaptonemal complex lengths and centromere indices of the autosomal bivalents exhibit a good correlation with light microscopical data on relative lengths and centromere indices of bivalents at diakinesis and of somatic metaphase chromosomes. Significant differences in total mean length were not found, neither among nuclei from the five individuals analyzed nor amng nuclei in different substages of pachytene. The absolute lengths of the individual bivalents were however found to vary among different nuclei, the maximum difference exceeding the estimated reconstruction and measuring error. It is furthermore shown that each of the five acrocentric bivalents is capable of organizing a nucleolus but that in most cases less than five nucleoli are present in each nucleus. A short piece of synaptonemal among nuclei in different substages of pachytene. The absolute lengths of the individual bivalents were however attachment site of the telomeres on the nuclear envelope.

\section{INTRODUCTION}

Meiosis in the human male has during the recent years been analyzed in great detail in the light microscope with various histological and cytogenetical methods. These observations have elucidated the normal development of the seminiferous tubules, the sequence of morphological changes of the nuclei during meiosis and in particular the morphology of the bivalents at diakinesis $(25,45)$. Meiosis has also 
been analyzed in a number of individuals with autosomal or sex chromosome aneuploidy or with chromosome rearrangements $(25,45)$. Furthermore, information is now accumulating on the frequency of meiotic non-disjunction and on the transmission of aberrant karyotypes $(6,15)$.

The application of different banding techniques to meiotic chromosomes has demonstrated a banding pattern which is almost identical to that of somatic metaphase chromosomes $(7,32)$. This has permitted the identification of all bivalents and has made it possible to determine the number and localization of chiasmata on the individual bivalents. With this approach, HULTÉN (26) found a good correlation between relative chiasma frequencies and the relative bivalent lengths at diakinesis.

The limitation of karyotype analyses with light microscopical methods is the relatively low resolution obtainable with this method. A more detailed picture of chromosome pairing during the meiotic prophase can be obtained through the analysis of the synaptonemal complex - a tripartite structure which is present between homologous chromosomes in pachytene. (For general reviews on the structure and function of the synaptonemal complex, see 18, 35, 52). This structure is easily identified in the electron microscope and can be followed by serial sectioning and reconstruction of whole nuclei. The method has successfully been used to establish the chromosome number and the absolute lengths of zygotene and/or pachytene bivalents in a variety of organisms $(2,16,17,20$, $24,33,34,40,53)$. Also the sequence of events ultimately resulting in regular disjunction of the homologous chromosomes at anaphase I has been characterized with this method in several organisms $(19,41,49,53)$.

Only relatively limited information is at present available on the ultrastructure of the pachytene karyotype in man. SOLARI and TRES (48) reported the presence of a piece of synaptonemal complex extending up to $1 \mu \mathrm{m}$ from the attachment sites on the nuclear envelope of the synapsed telomerès of the $\mathrm{X}$ and $\mathrm{Y}$ chromosomes. HULTEN et al. $(27,28)$ considered the possibility of an altered ultrastructure of the synaptonemal complex in spermatocyte nuclei from an oligochiasmatic man but found normal synaptonemal complexes in a patient suffering from xeroderma pigmentosum. Finally, MOSES et al. (36) were able to detect 22 bivalents and the $X Y$ bivalent by surface spreading techniques. As the position of the centromeres could not always be established unequivocally in the spread material, identification of individual bivalents had to be based primarily on absolute and relative lengths of synaptonemal complexes. It was therefore only possible to classify a fraction of the bivalents.

The present report aims to extend the information on the normal pachytene karyotype of human males and attempts to correlate the observations with available light microscopical data on relative bivalent lengths and position of the centromeres.

\section{MATERIALS AND METHODS}

\subsection{Materials}

Testicular biopsies were obtained from Dr. M. Hultén, Regional Cytogenetics Laboratory, East Birmingham Hospital; from Dr. N. E. SKAKKEB EK, Laboratory of Reproductive Biology, University Dept. of Obstetrics and Gynecology, Rigshospitalet, Copenhagen; and from Dr. J. LindenberG, Dept. of Surgery K, Frederiksberg Hospital, Copenhagen. The material consist of testicular biopsies from four normal fertile men undergoing vasectomy (cases 2-5). In addition, testicular biopsies were obtained from one azoospermic man (case 1). The patient lacked ductus deferens and the main part of the epididymis was atrophic. Histological analysis revealed however a quantitatively normal spermatogenesis in the majority of the

Abbreviations: $\mathrm{Cl}$, centromere index. s.d., standard deviation. 
seminiferous tubules (SKAKKEB ÆK, personal communication). The ultrastructure of the meiotic prophase of the azoospermic man was similar to that of the four normal males and is thus not discussed separately.

\subsection{Electron microscopy}

Immediately after removal, the testicular biopsies were placed in a $4 \%$ phosphate buffered $(0.06 \mathrm{M}, \mathrm{pH} 7.2)$ glutaraldehyde solution with a purification index of about 0.2 (1), cut in pieces with a diameter of approximately 1 $\mathrm{mm}$, transferred to fresh glutaraldehyde and fixed for $3-3^{1} / 2$ hours at room temperature. After two rinses, the tissue was osmicated in a $2 \%$ phosphate buffered osmiumtetraoxide solution at room temperature for 2 hours, washed twice in buffer, 4-5 times in distilled water, and left over night in distilled water at $4^{\circ} \mathrm{C}$. The biopsies were then fixed/stained in a $2 \%$ aqueous uranyl acetate solution at $60^{\circ} \mathrm{C}$ for 3 hours. After cooling to room temperature, the tissue was dehydrated in a graded alcohol series, embedded in SPURR's low viscosity resin (50) and polymerized for 24 hours at $70^{\circ} \mathrm{C}$.

Thick sections (about $1 \mu \mathrm{m}$ ) of the seminiferous tubules were examined in the light microscope for a preliminary identification of meiotic stages. Nuclei in the relevant stages of meiotic prophase were serially sectioned on a Reichert Om U3 ultramicrotome equipped with a diamond knife. The serial sections were picked up on single slot grids without formvar film and thereafter transferred onto grids with supporting film, using a micromanipulator for maneuvering the grids during the transfer process. Sections were stained in a $5 \%$ aqueous uranyl acetate solution for $30 \mathrm{~min}$ at $50^{\circ} \mathrm{C}$, rinsed, and poststained in lead citrate (43) for $20 \mathrm{~min}$. The staining was carried out in an automatic staining apparatus which eliminates the risk of contamination during the staining procedure.

Sections were examined, and selected nuclei were photographed (usually 3 nuclei in parallel) in a Simens Elmiscope 102 at primary magnification of 4-5.000 times.

\subsection{Three dimensional reconstruction}

Three dimensional reconstructions were performed in the following way: The synaptonemal complex segments from ten sections were traced onto transparent plastic film. After having encompassed the whole nucleus the tracings of all synaptonemal complex segments of each bivalent were redrawn on a new sheet of plastic film together with the relevant section numbers. The projected lengths were measured and the absolute lengths calculated, taking into account the section thickness (estimated to be $0.08 \mu \mathrm{m}$ ) as described by Gillies (16). The measurements and calculations were performed on a Hewlett Packard digitizer (HP 9864A) and calculator (HP 9825A).

\section{RESULTS}

\subsection{General comments}

The pachytene stage is the most frequent stage of the meiotic prophase in seminiferous tubules suggesting that this stage is very long compared with the total duration of the meiotic prophase. This is in agreement with HeLLER and Clermont (22) who estimated the pachytene stage to occupy $65 \%$ of the total time spent in meiotic prophase. The latter lasts 23 days and the pachytene stage 16 days. The spermatogenic wave characteristic of the germinative epithelium in the rat (31) is not seen in man, but cells in the same stage of development appear to be clustered in the seminiferous tubule. Stage dependent changes in the distribution and morphology of cellular components such as Golge apparatuses, mitochondria, and centrioles were not observed during pachytene. The classification of the 22 reconstructed pachytene nuclei into a temporal sequence is therefore entirely based on the degree of condensation of the autosomal chromatin assuming a progressive condensation of the chromatin during pachytene. Following this criterium, the 22 nuclei represent a continuous sequence of pachytene stages.

\subsection{The pachytene cell}

The ultrastructure of early, mid, and late pachytene cells is shown in Figures 1-3. In 


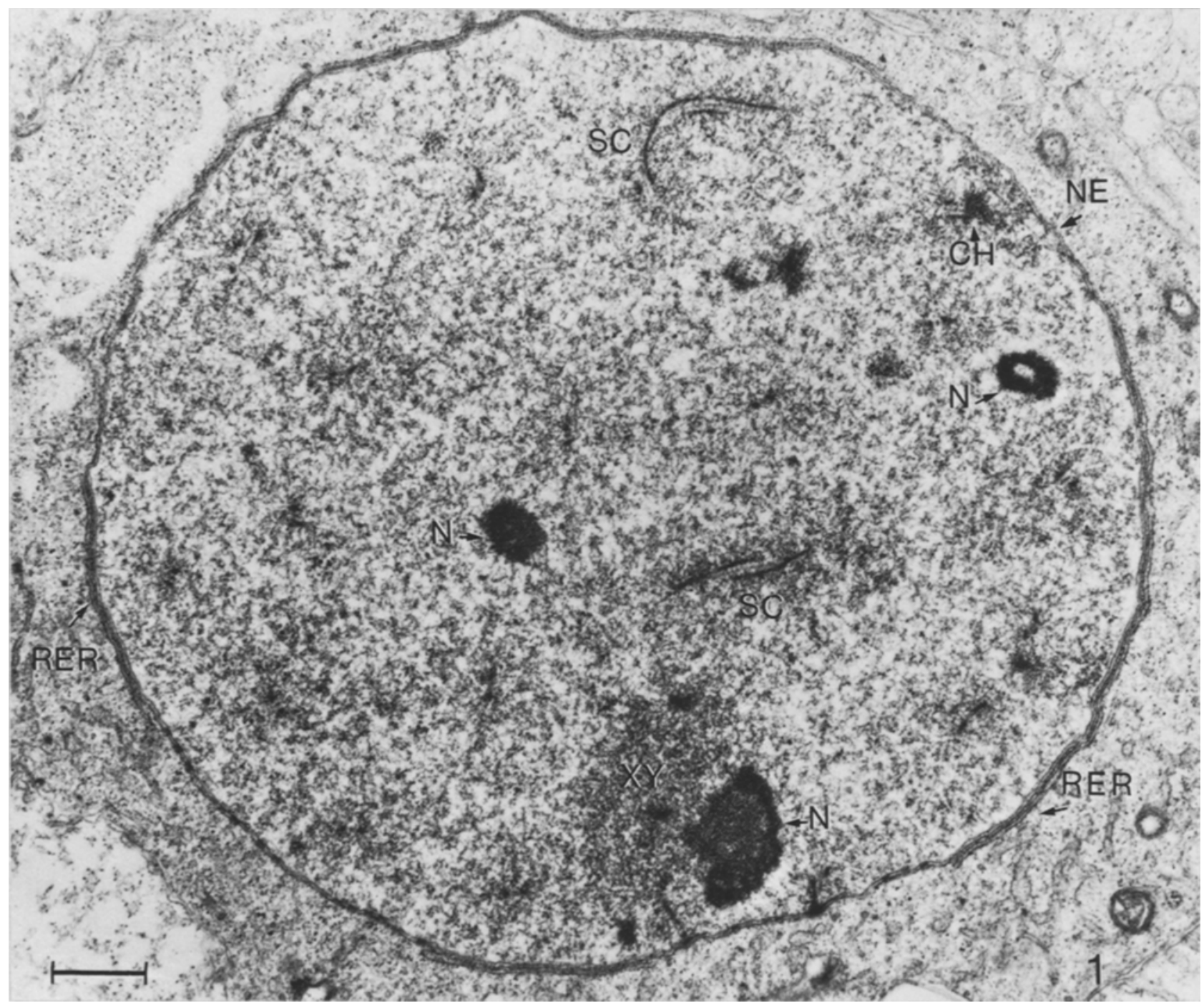

Figure 1. Survey micrograph of an early pachytene nucleus. Synaptonemal complexes (SC), centromeric heterochromatin $(\mathrm{CH})$ and small free nucleoli $(\mathrm{N})$ are present in the nucleoplasm. The $\mathrm{XY}$ body $(\mathrm{XY})$ is associated with a major nucleolus (N). The nuclear envelope (NE) is at four locations bordered by a sheet of rough endoplasmic reticulum (RER). Note the decondensed chromatin of the bivalents.

$(\mathrm{Bar}=1.0 \mu \mathrm{m})$

comparison with the Sertoli cells the cytoplasm of the spermatocytes is characterized by a low amount of ribosomes and few mitochondria with poorly developed christae. The Golgi cisternae and vesicles are abundant and one major aggregation of Golgi apparatuses is found near the nucleus. Inside this aggregate are present the two centrioles at a distance of one to two $\mu \mathrm{m}$ from the nuclear envelope and one to two $\mu \mathrm{m}$ from each other. In all cells examined, the centrioles are duplicating, as recognized by the presence of a small centriole forming at right angle to the old centriole (Figure 21). Structure and position of the 


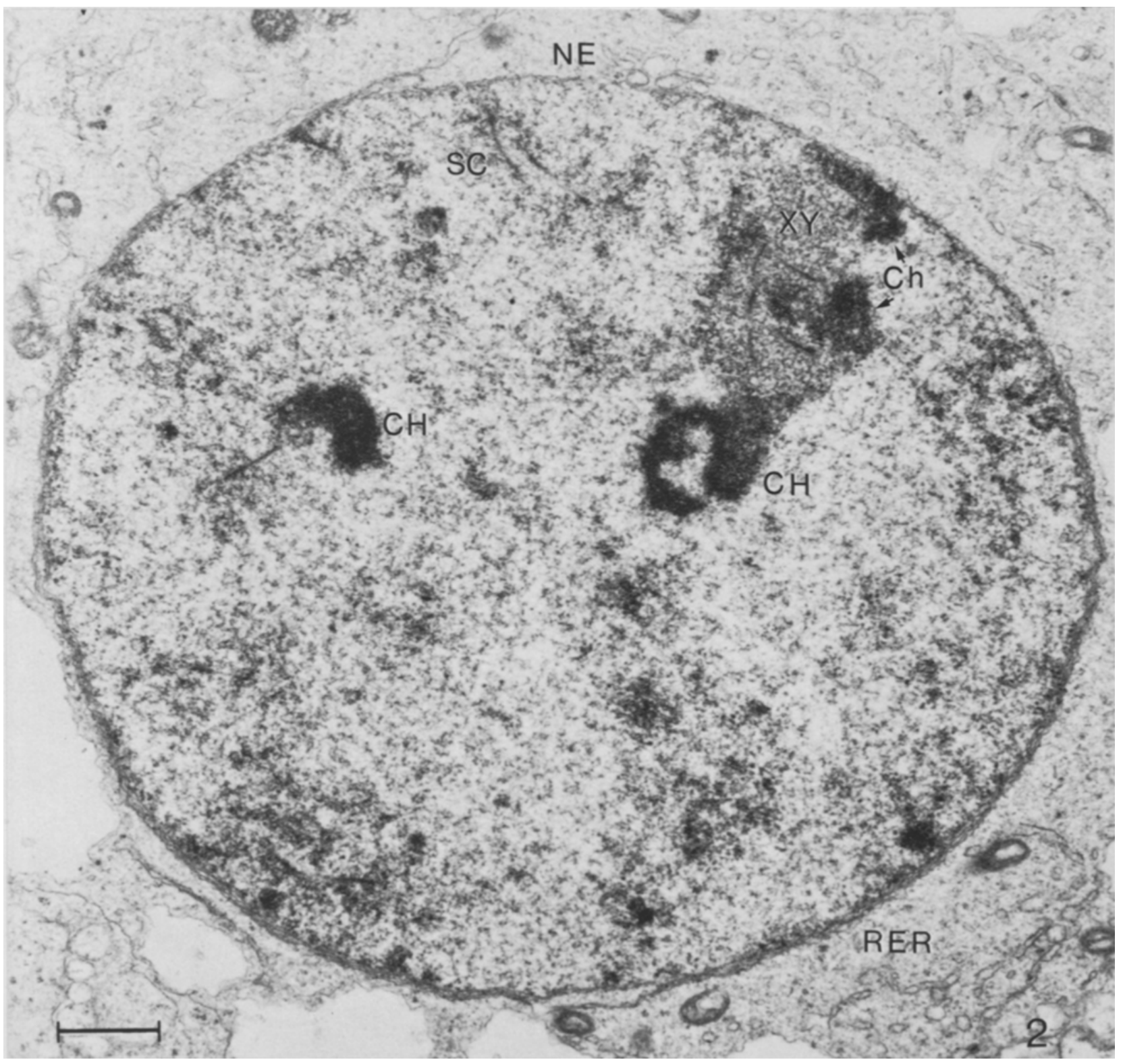

Figure 2. Survey micrograph of a mid pachytene nucleus. The chromatin appears more condensed around the synaptonemal complex (SC) compared to the nucleus depicted in Figure 1. Large blocks of centromeric heterochromatin $(\mathrm{CH})$ are visible. The $\mathrm{XY}$ body $(\mathrm{XY})$ contains regions of compacted chromatin $(\mathrm{Ch})$. Sheets of rough endoplasmic reticulum (RER) border the nuclear envelope (NE).

$(\mathrm{Bar}=1.0 \mu \mathrm{m})$

centrioles were similar in the 22 cells. A granule, with a diameter of $300 \AA$ is evident at one end of the centriolar lumen (Figure 4).
The endoplasmic reticulum of the cytoplasm is vesiculated and sheets of uni-, or multilayered rough endoplasmic reticulum fre- 


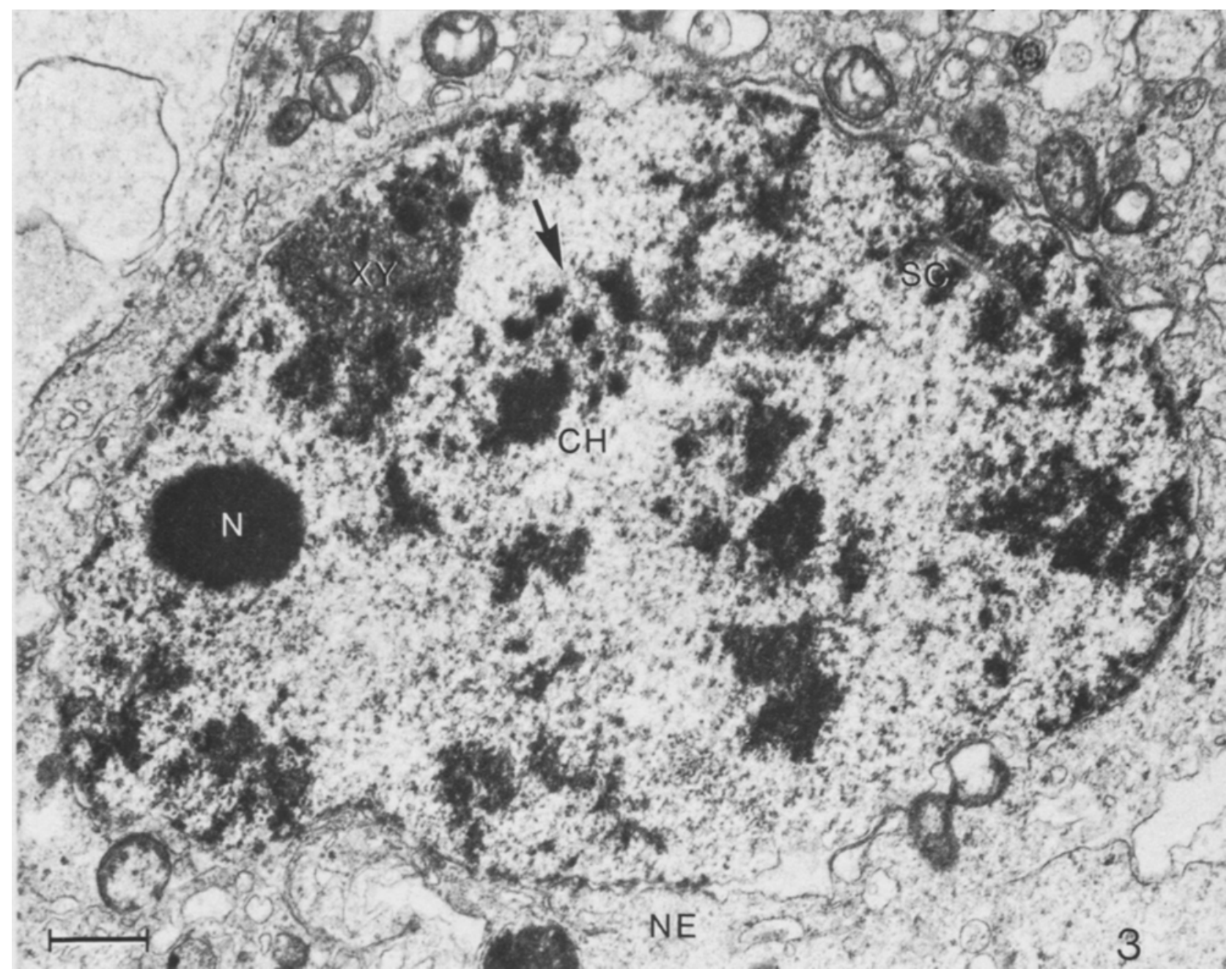

Figure 3. Survey micrograph of a late pachytene nucleus. The chromatin is heavily compacted around the synaptonemal complexes (SC). Note the $\mathrm{XY}$ body $(\mathrm{XY})$, the centromeric heterochromatin $(\mathrm{CH})$, and the nucleolus (N). The arrow denotes the diffuse heterochromatin corresponding to the secondary constriction. The two membranes of the nuclear envelope (NE) are separated at several locations.

$(\mathrm{Bar}=1.0 \mu \mathrm{m})$

Figure 4. Golgi apparatuses (GA) and centrioles (Ct) in the cytoplasm near the nuclear envelope (NE) of a pachytene spermatocyte. Note the dense granule (arrow) in the lumen of the centriole.

$(\mathrm{Bar}=0.2 \mu \mathrm{m})$

Figure 5. Annulate lamellae (AL) and rough endoplasmic reticulum (RER) of a pachytene spermatocyte. The rough endoplasmic reticulum borders the nuclear envelope.

$(B a r=0.2 \mu \mathrm{m})$ 

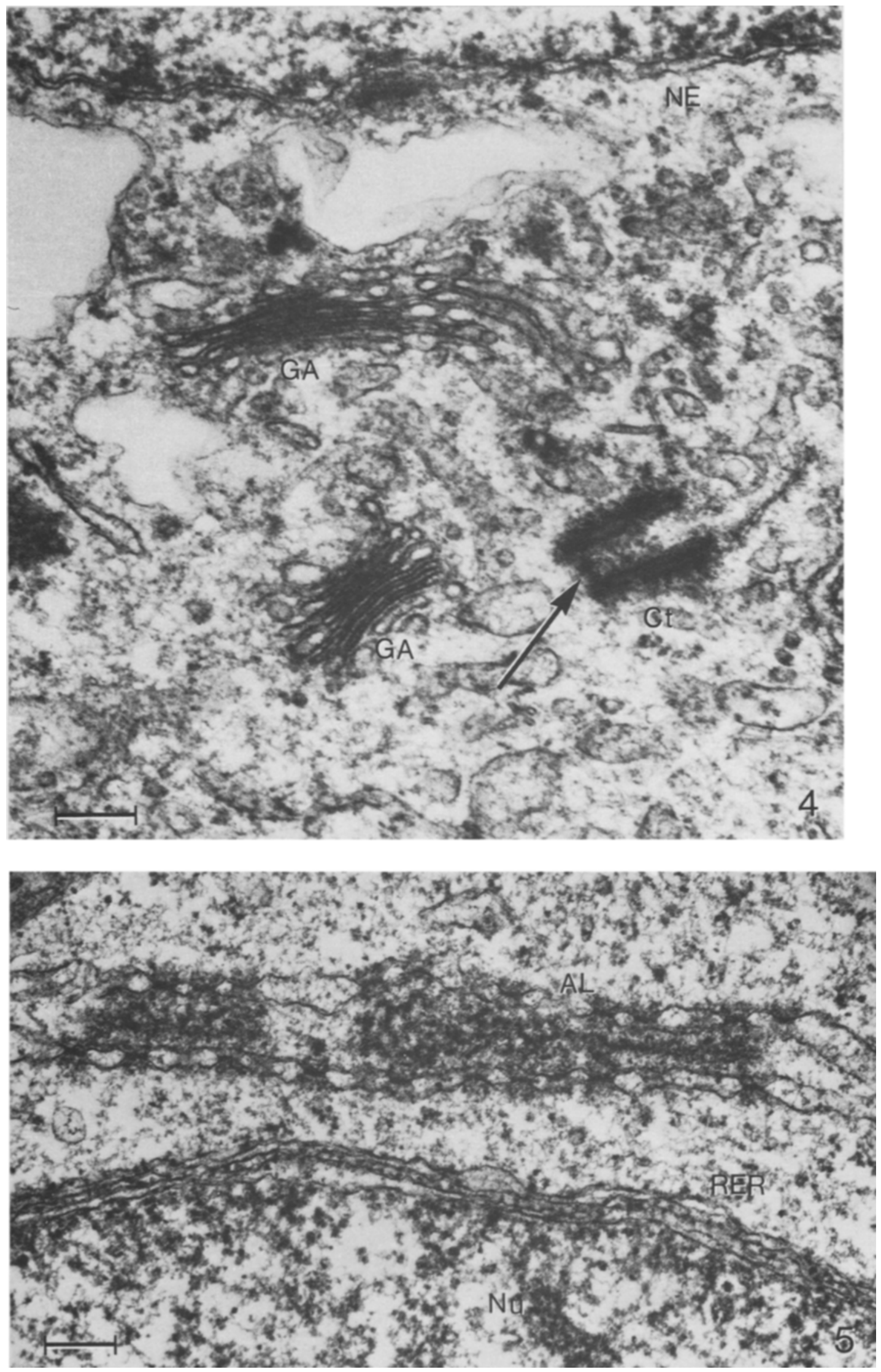

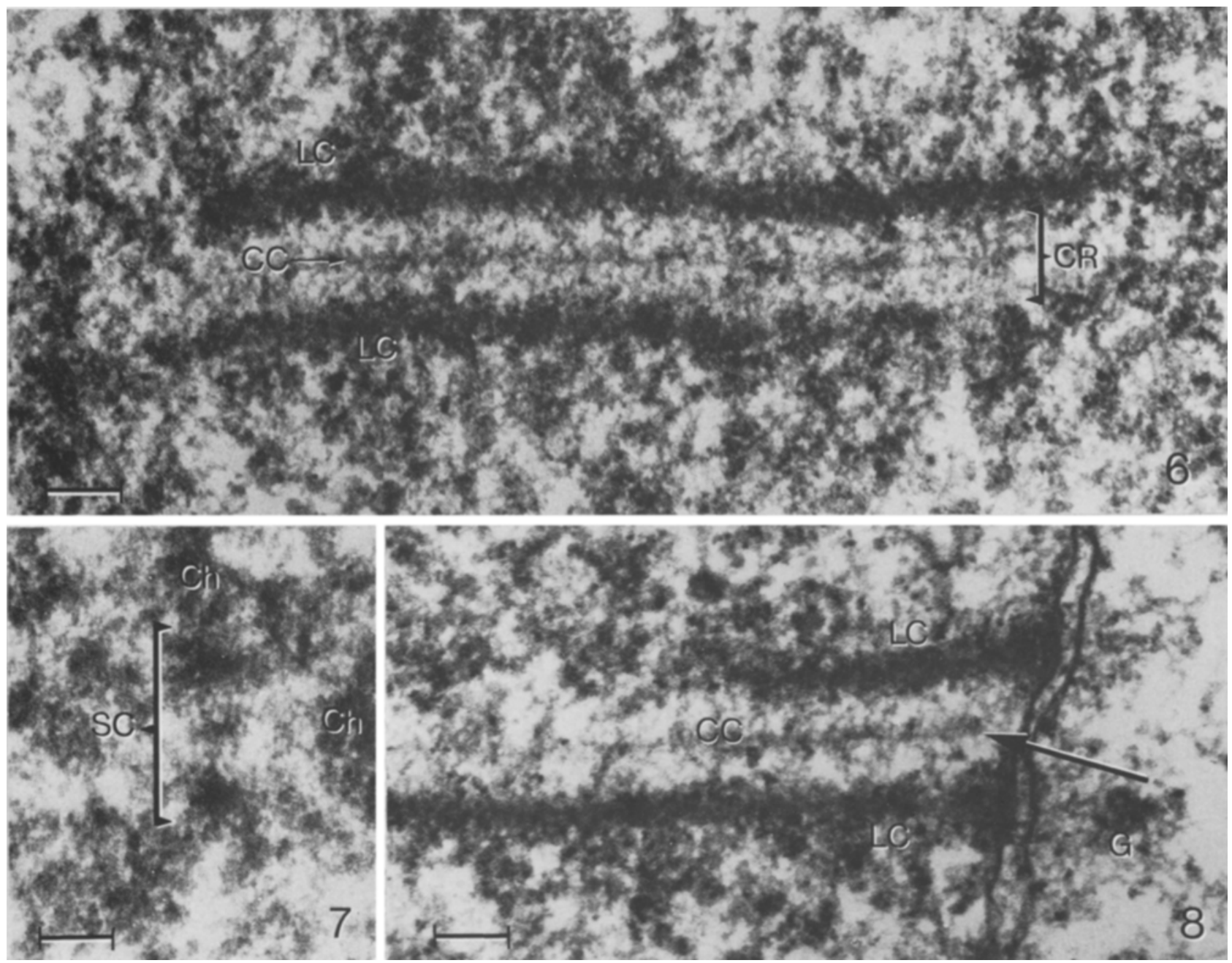

Figure 6. A high magnification of a longitudinal section of the synaptonemal complex from a pachytene spermatocyte. The synaptonemal complex consists of two electron dense lateral components (LC) $300-400 \AA$ in diameter and a central region, $1100-1200 \AA$ wide. The central region $(C R)$ contains an amorphous central component (CC) with a diameter of $100-300 \AA$. The central component is connected to the lateral components by irregularly spaced traversing filaments.

$(\mathrm{Bar}=0.1 \mu \mathrm{m})$

Figure 7. A cross section of pachytene bivalent. The chromatin $(\mathrm{Ch})$ encloses the components of the synaptonemal complex (SC).

$(\mathrm{Bar}=0.1 \mu \mathrm{m})$

Figure 8 . The attachment site of a bivalent to the nuclear envelope of a pachytene spermatocyte. The lateral components (LC) are associated with the inner membrane of the nuclear envelope through a conus of material similar in density to the lateral components. The central component (CC) terminates $500 \AA$ from the inner membrane (arrow). Fine filaments penetrate the nuclear envelope from the attachment sites of the lateral components and extend a few hundred $\AA$ into the cytoplasm. A granule $(\mathrm{G})$ about $600 \AA$ in diameter is associated with one of the bundles of filaments.

$(\mathrm{Bar}=0.1 \mu \mathrm{m})$ 


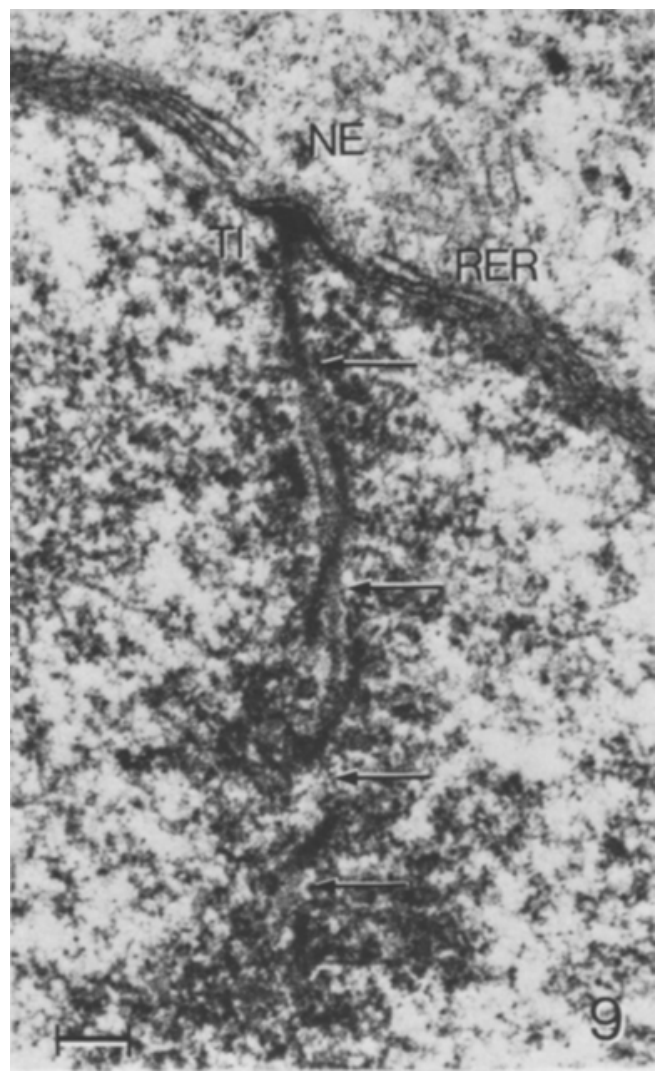

Figure 9. The attachment site of a pachytene bivalent to the nuclear envelope (NE). Note that the sheets of rough endoplasmic reticulum (RER) are interrupted at the attachment site. The bivalent is twisted 180 degrees at four locations (arrows). T1, telomeres. $($ Bar $=0.2 \mu \mathrm{m})$

quently form a sheath around the nuclear envelope (Figure 5). This multilayered sheath was especially prevalent in the cells from case 2. In addition, each of the cells analyzed had one complex of stacked annulated lamellae located in the vicinity of the nucleus (Figure 5). The nuclear pores are clustered, the groups being distributed evenly throughout the nuclear envelope.

\subsection{Synaptonemal complexes}

In all 22 nuclei investigated, the 22 autosomal chromosome pairs are present as bivalents each with a continuous synaptonemal complex from telomere to telomere. The fine structure of the synaptonemal complex and its dimensions are similar to those described for other eukaryotic organisms (52). Each of the homologous chromosomes is flanked by a lateral component which is closely associated with the chromatin of the two sister chromatids. The lateral components are electron dense with a filamentous substructure and with a round to ovoid shape in cross section. The diameter varies between 300 and $400 \hat{A}$. The two lateral components are held in register at a distance of 1100 to $1200 \AA$ by the central region which contains a medially located central component with a diameter of 100 to $300 \AA$. The central component is connected to the lateral components by irregularly spaced traversing filaments (Figures 6-8).

The telomeres of all the bivalents are attached to the inner membrane of the nuclear envelope through local thickenings of the lateral components. As seen in Figure 8, a number of fine filaments penetrate both membranes of the nuclear envelope and extend up to $1000 \AA$ into the cytoplasm. Occasionaliy, the filaments terminate in a dense granule, $600-700 \dot{A}$ in diameter (Figure 8 ). The sheath of multilayered endoplasmic reticulum described above, is consistently absent at the attachment sites of the telomeres (Figure 9).

Local modifications of the individual components of the synaptonemal complex which have been noted in several other organisms (see 18 for a recent review) were not observed. The nodes in the central component described by Gillies (16), ZiCKLER (53), and others and the dense nodules which are found in association with the synaptonemal complex in Drosophila (5) were not observed in the spermatocyte nuclei.

\subsection{Centromeric heterochromatin and knobs}

Each pachytene bivalent contains one large block of compacted chromatin associated with the lateral components of the synaptonemal complex (Figures 10 and 11). In addition, a number of bivalents possess up to three smallet chromatin condensations, hereafter called knobs, with an electron density and ultrastructure similar to that of the larger blocks (Figure 12). The reconstructions have revealed 

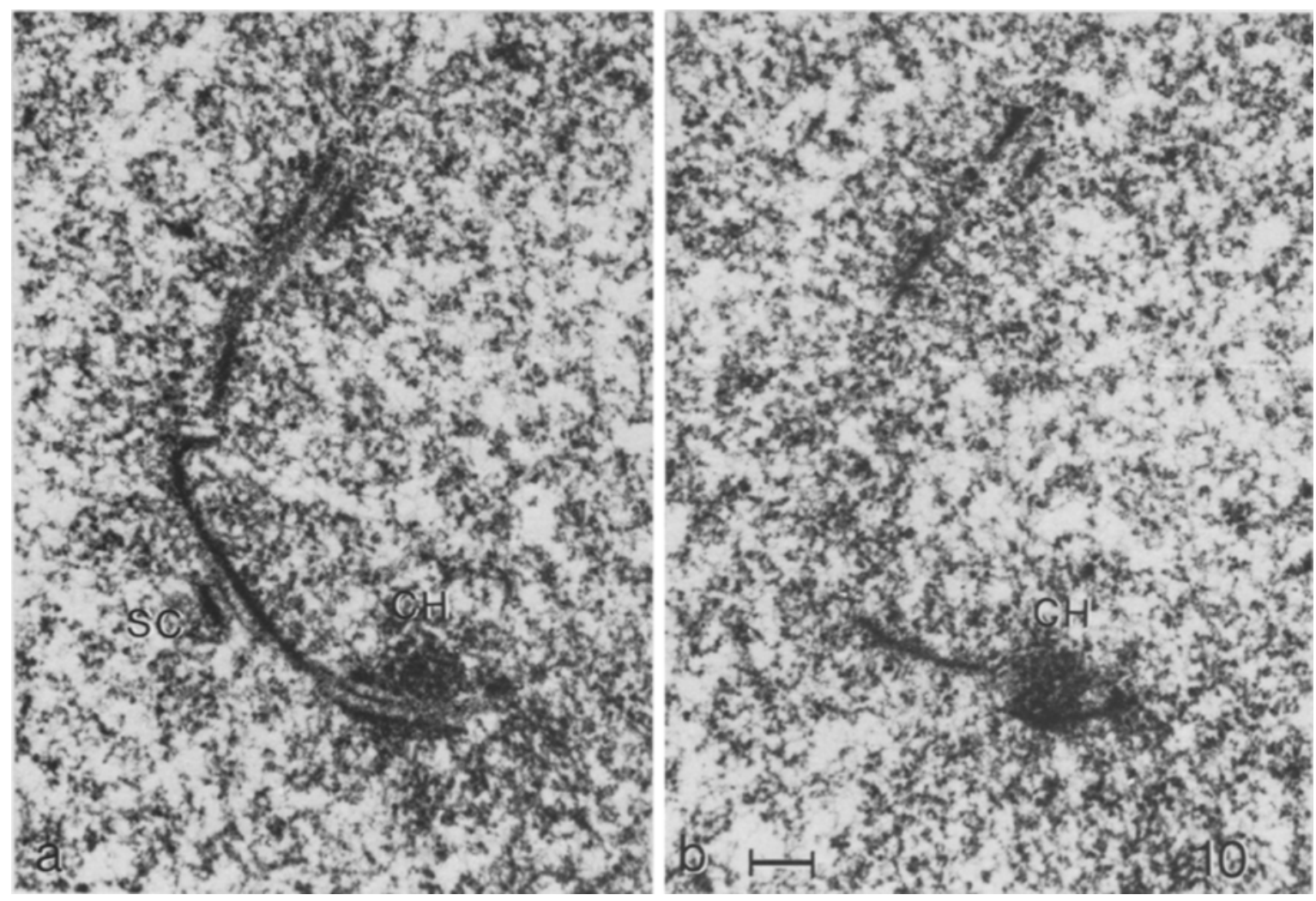

Figure 10. Two consecutive sections through the centromeric heterochromatin of a bivalent at early pachytene. The synaptonemal complex (SC) passes unaltered through the centromeric heterochromatin $(\mathrm{CH})$.

$(\mathrm{Bar}=0.2 \mu \mathrm{m})$

that the relative position of the larger blocks of chromatin corresponds to the position of the primary constriction of diakinesis bivalents and somatic metaphase chromosomes (see HuLTÉN, 26 , for light microscope observations). In the majority of the meta- and submetacentric bivalents, the compacted chromatin is not symmetrically distributed around the synaptonemal complex but in the shape of a kidney as illustrated in Figure 11. In the acrocentric bivalents, the centromeric heterochromatin is evenly distributed around the synaptonemal complex and extends to the telomeres of the short arms (Figure 13). Inside the centromeric heterochromatin of all meta- and submetacentric bivalents, material of low electron density is present (Figure 11). This material is attached to the lateral components of the synaptonemal complex and probably marks the position of the centromere. A morphologically distinguishable centromere could only be identified in the acrocentric bivalents of the

Figure 11. Three consecutive sections through the centromeric heterochromatin of a bivalent in mid pachytene. The centromeric heterochromatin $(\mathrm{CH})$ is compacted along the synaptonemal complex (SC) with a region of lower density in the middle of the chromatin (arrow).

$(\mathrm{Bar}=0.2 \mu \mathrm{m})$ 


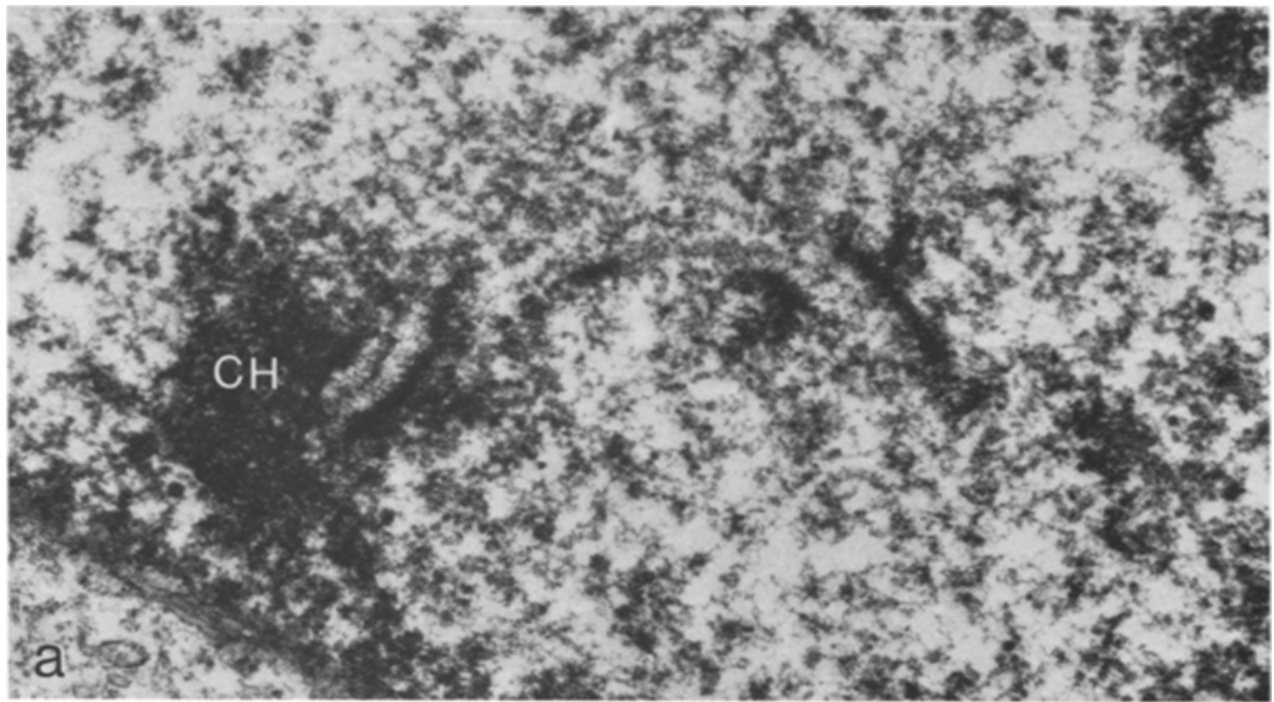

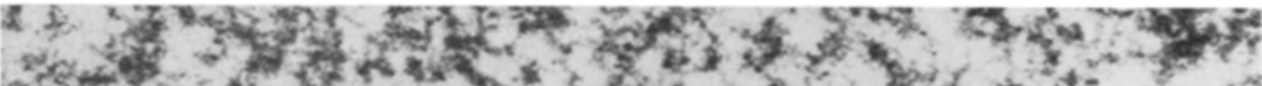

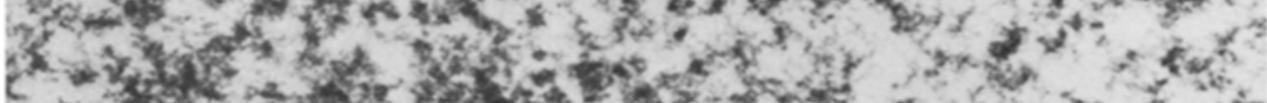
W *1. 2. 3 .

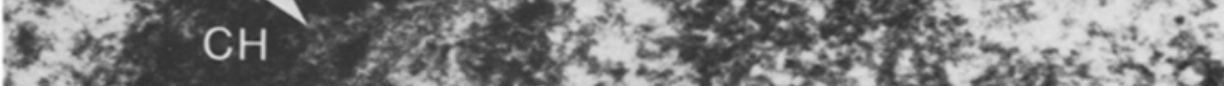

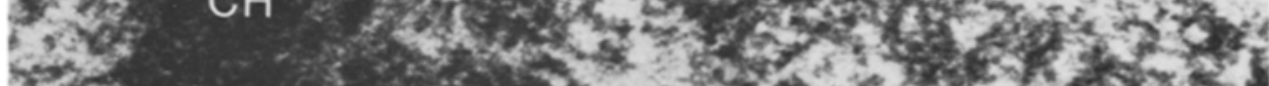

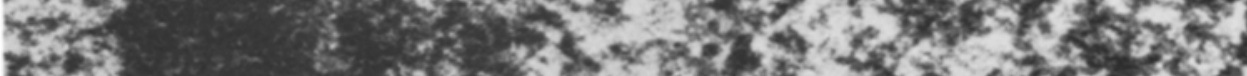

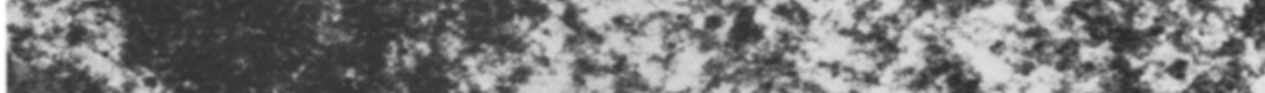

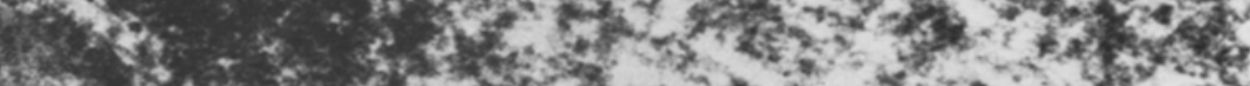

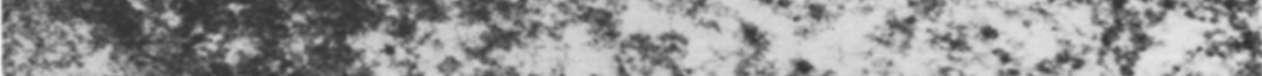

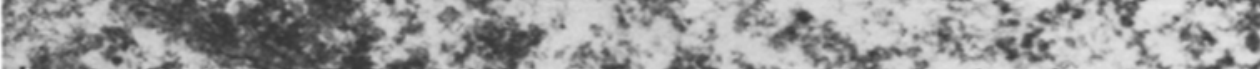

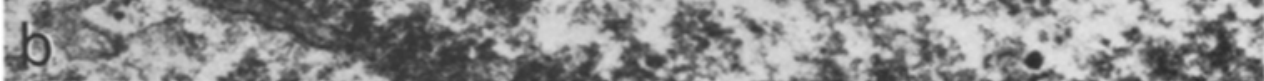

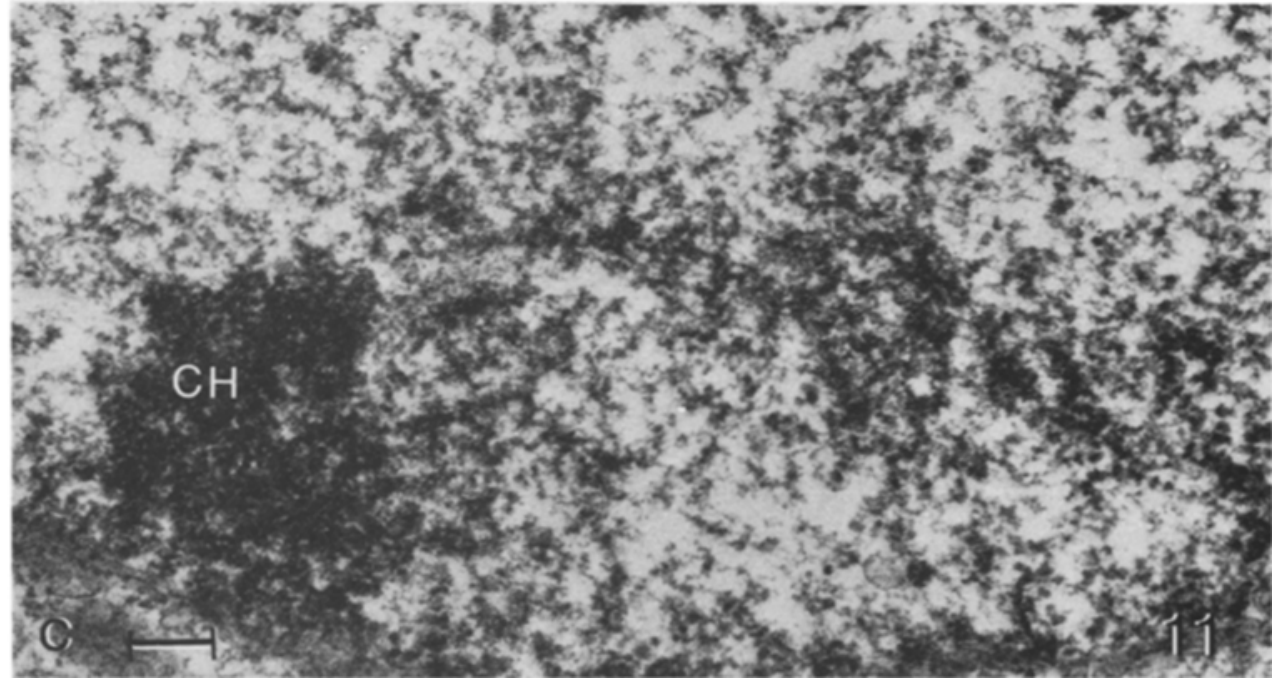



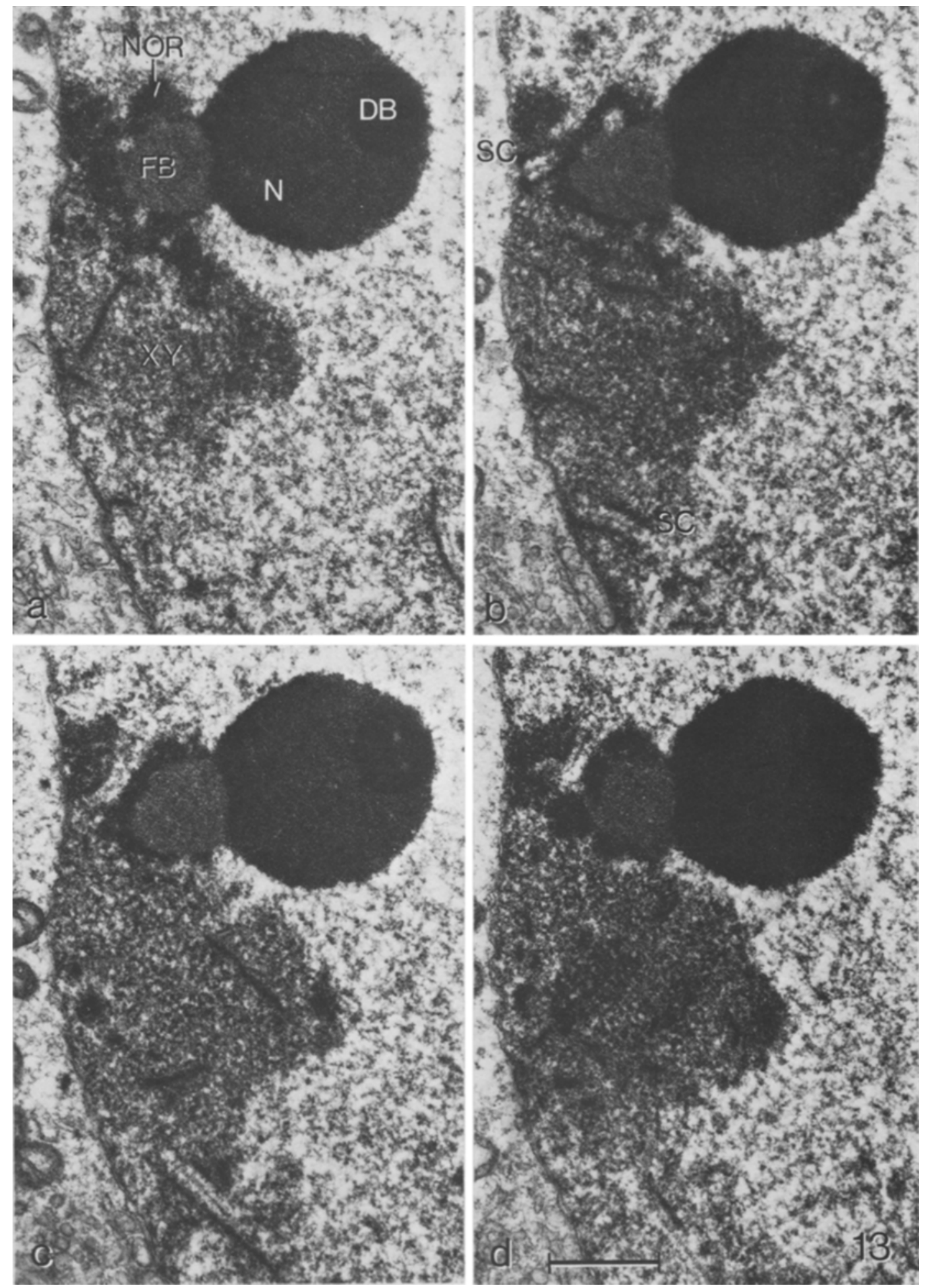

Figure 13. Four consecutive sections through the nucleolus $(\mathrm{N})$ and the nucleolus organizer region (NOR) of an acrocentric bivalent at mid pachytene. The chromatin is condensed around the synaptonemal complex (SC) and extends to the attachment site on the nuclear envelope of the short arm. The chromatin is on one side associated with a $X Y$ body $(X Y)$. The nucleolus is attached to the chromatin through a filamentous sphere of low density (FB), marking the position of the nucleolus organizer. A body of high electron density (DB) is present inside the compact nucleolus. Compare with Figures 15, 16, and 17. (Bar $=0.5 \mu \mathrm{m})$ 

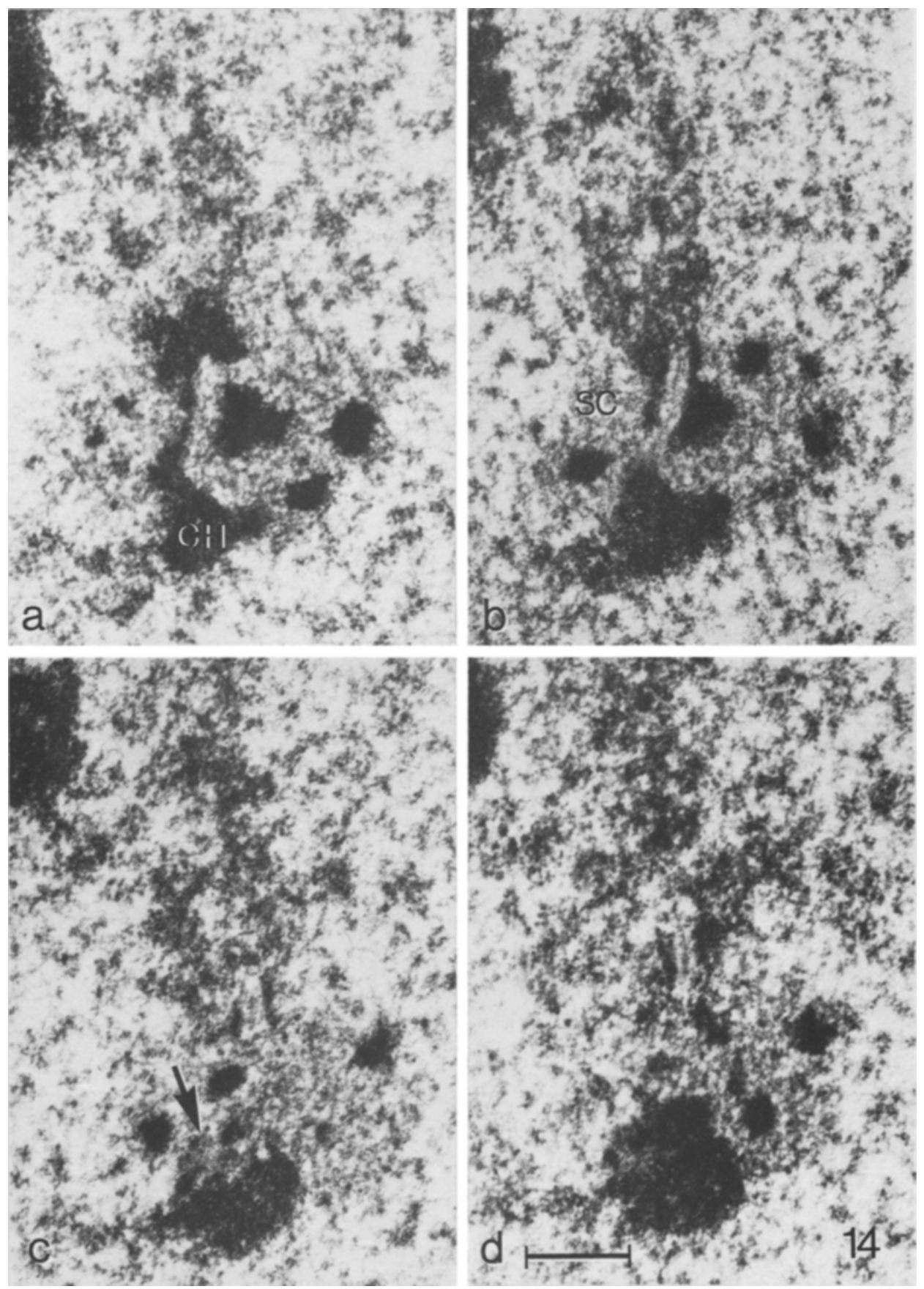

Figure 14. Four consecutive sections through the centromeric heterochromatin of bivalent $9 . \mathrm{CH}$, compacted chromatin of the centromere region. SC, synaptonemal complex. Arrow in figure $\mathrm{c}$ denotes the material marking the position of the centromere.

$(\mathrm{Bar}=0.5 \mu \mathrm{m})$ 
Table I

Chromosomes with nucleolus organizer region in human spermatocytes.

\begin{tabular}{|c|c|c|c|c|}
\hline $\begin{array}{l}\text { Nucleus } \\
\text { number }\end{array}$ & $\begin{array}{c}\text { Stage in } \\
\text { pachytene }\end{array}$ & $\begin{array}{l}\text { Major nucleolus } \\
\text { associated with } \\
\text { bivalent(s) } \\
\text { number(s): }\end{array}$ & $\begin{array}{l}\text { Small nucleolus } \\
\text { associated with } \\
\text { bivalent(s) } \\
\text { number(s): }\end{array}$ & $\begin{array}{l}\text { Number of major } \\
\text { nucleoli not associated } \\
\text { with bivalents }\end{array}$ \\
\hline 10 & Early & 15 & $13,14,22$ & $2^{+}$ \\
\hline $\begin{array}{r}1 \\
3 \\
4 \\
20 \\
21\end{array}$ & $\begin{array}{c}\text { Early/mid } \\
- \\
- \\
- \\
-\end{array}$ & $\begin{array}{c}13 \\
21 \\
14+21^{*} \\
- \\
14\end{array}$ & $\begin{array}{l}- \\
- \\
- \\
- \\
-\end{array}$ & $\begin{array}{l}0 \\
0 \\
0 \\
1 \\
0\end{array}$ \\
\hline $\begin{array}{r}2 \\
7 \\
9 \\
11 \\
12 \\
17 \\
18 \\
19 \\
22\end{array}$ & $\begin{array}{c}\text { Mid } \\
- \\
- \\
- \\
- \\
- \\
- \\
- \\
-\end{array}$ & $\begin{array}{c}13 \\
14 \\
13 \\
13 \\
15 \\
14 \\
22 \\
15 \\
-\end{array}$ & $\begin{array}{c}- \\
- \\
- \\
- \\
- \\
15 \\
- \\
- \\
-\end{array}$ & $\begin{array}{l}0 \\
0 \\
1 \\
0 \\
0 \\
0 \\
0 \\
0 \\
1^{+}\end{array}$ \\
\hline $\begin{array}{r}8 \\
13 \\
14 \\
15 \\
16\end{array}$ & $\begin{array}{c}\text { Mid/late } \\
- \\
- \\
- \\
-\end{array}$ & $\begin{array}{c}- \\
13+21^{*} \\
13 \\
21 \\
21\end{array}$ & $\begin{array}{c}- \\
- \\
- \\
- \\
13,15,22\end{array}$ & $\begin{array}{l}2 \\
0 \\
1 \\
0 \\
0\end{array}$ \\
\hline $\begin{array}{l}5 \\
6\end{array}$ & Late & $\begin{array}{c}13+14^{*} \\
21\end{array}$ & $\begin{array}{c}15,21,22 \\
13,14,15,22\end{array}$ & $\begin{array}{l}1 \\
1\end{array}$ \\
\hline
\end{tabular}

*, two chromosomes associated with the same nucleous

+ , a major nucleolus associated with the $\mathrm{XY}$ body

the synaptonemal complex similar to the centromeric heterochromatin. Whether the observed difference in frequency of knobs on individual bivalents in different nuclei of the same individual is dependent upon the stage of development, different indvididuals, or reflects natural polymorphism is not known.

\subsection{The nucleolus}

A morphologically distinguishable region equivalent to the secondary constriction seen in the light microscope was not observed in any of the acrocentric bivalents. The present investigation demonstrates that all of the five acrocentric bivalents are capable of organizing a nucleolus but that in most cases less than five nucleoli are present in each nucleus (Table I and Figure 23). In 19 of the 22 nuclei examined one of the acrocentric bivalents was attached to a large nucleolus with a diameter of about 1.5 $\mu \mathrm{m}$ (Figures 13 and 15). In addition, smaller nucleoli with diameters ranging from $0.2 \mu \mathrm{m}$ to $0.5 \mu \mathrm{m}$ were frequently found attached to different acrocentric bivalents (Figure 16 and Table I). In a few cases, major nucleoli were lying free in the nucleoplasm or were associated with the $\mathrm{XY}$ body (Figure 17). In the remaining 3 nuclei, one or two major nucleoli were lying free in the nucleoplasm and none of the acrocentric bivalents were associated with a nucleolus. 

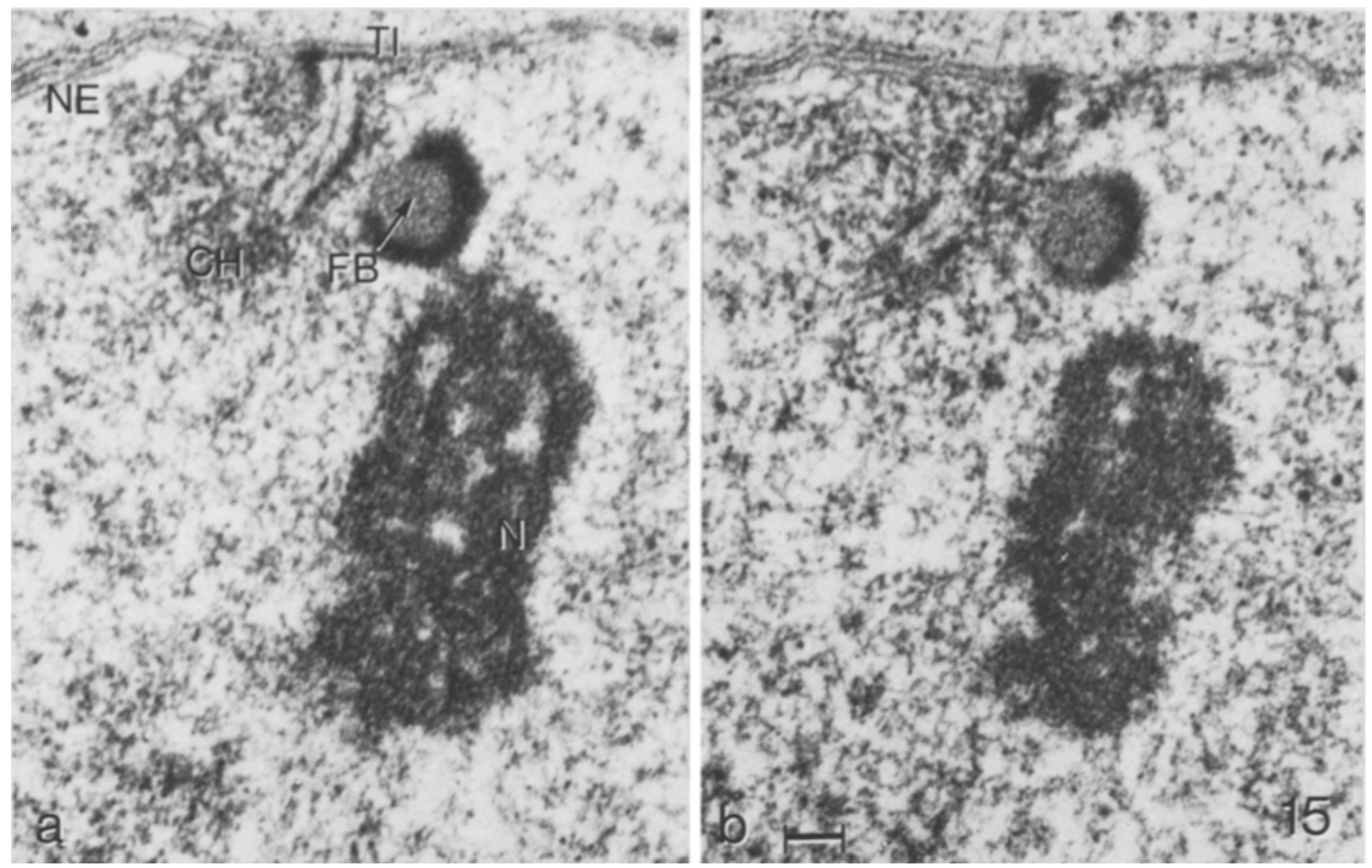

Figure 15. Two consecutive sections through an acrocentric bivalent at early pachytene. The centromeric heterochromatin $(\mathrm{CH})$ and the chromatin of the short arm are decondensed. A large nucleolus $(\mathrm{N})$ is associated with the chromatin of the short arm through a filamentous sphere of low density (FB) marking the position of the nucleolus organizer. The sphere is partially enclosed by dense material (arrow). The telomeres (II) are attached to the nuclear envelope (NE). Compare with Figures 13, 16, and 17.

$(B$ ar $=0.2 \mu \mathrm{m})$

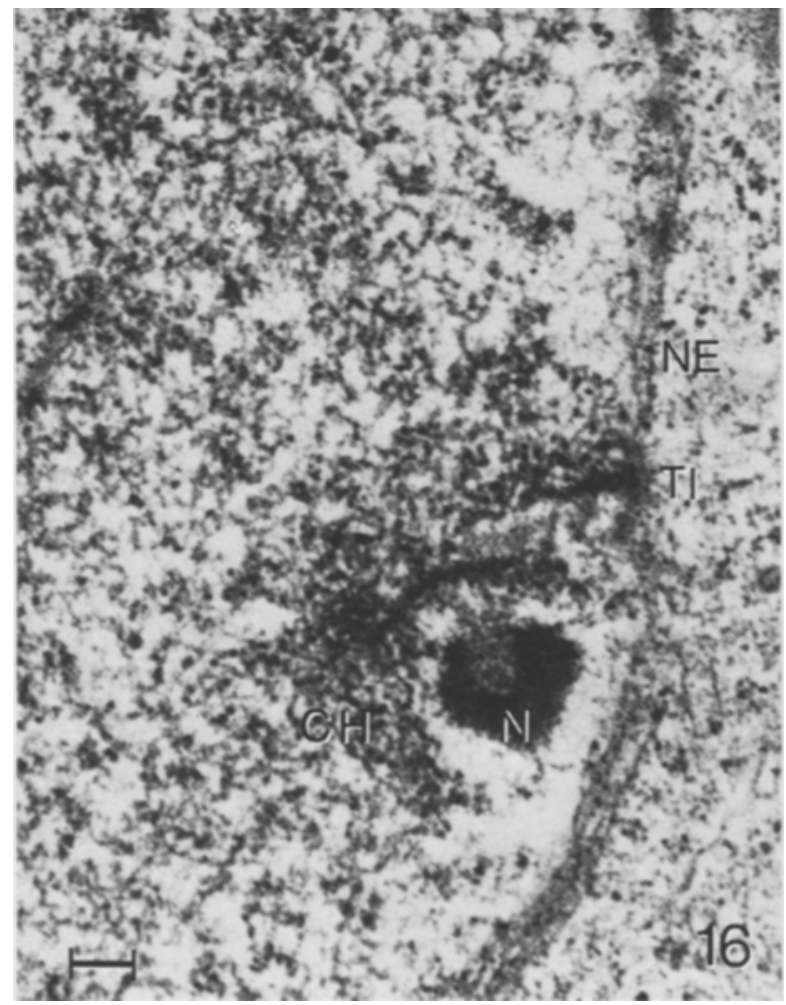

Distinct nucleolus organizer regions can not be identified in pachytene spermatocytes. The nucleoli are associated with the chromatin of the short arms through a filamentous sphere of low density (Figures 13, 15 and 16). The presence of this sphere in free nucleoli (Figure 17) demonstrates that this material is not an integrated part of the chromosomes.

The morphology of large and small nucleoli at early and mid to late pachytene is illustrated in Figures 13, 15, and 16.

Figure 16. A section through an acrocentric bivalent at early pachytene. The centromeric heterochromatin $(\mathrm{CH})$ and the chromatin of the short arm are decondensed. A small nucleolus $(\mathrm{N})$ is associated with the chromatin of the short arm through a filamentous sphere of low density (FB). Tl, telomere. Compare with Figures 13, 15, and 17.

$(\mathrm{Bar}=0.2 \mu \mathrm{m})$ 


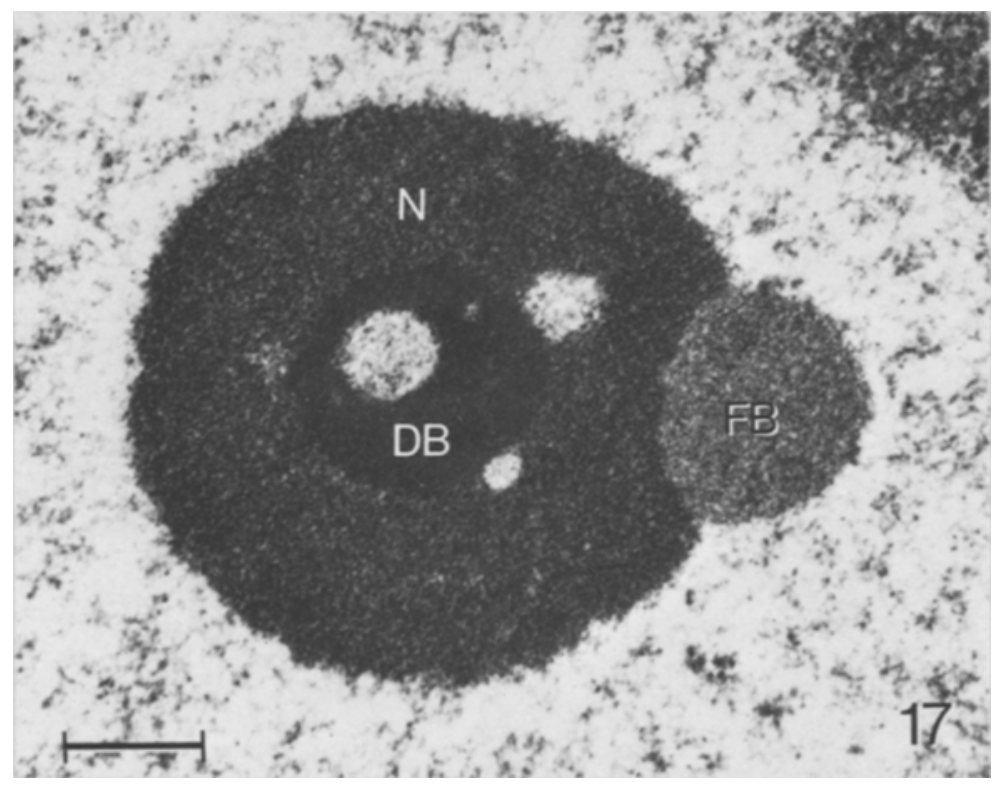

Figure 17. A major free nucleolus $(N)$ in the nucleoplasm of a mid pachytene spermatocyte. The filamentous region of the nucleolus organizer (FB) is still associated with the nucleolus. Inside, the free nucleolus contains a dense body (DB). Compare with Figures 13, 15, and 16.

$(\mathrm{Bar}=0.5 \mu \mathrm{m})$

\subsection{The XY body}

At early pachytene the XY bivalent is condensed as a discrete body which is connected to the nuclear envelope through the attachment sites of the telomeres of the $X$ and $Y$ chromosomes. As shown in Figure 18, the chromatin of the $\mathrm{XY}$ body is less compacted than the centromeric heterochromatin. One short piece of synaptonemal complex extending up to $1 \mu \mathrm{m}$ from the attachment sites of the $X$ and $Y$ telomeres was revealed in 19 of the 22 nuclei analyzed (Table II). It is seen in Table II that the length of the paired region varies between 0.1 and $1.0 \mu \mathrm{m}$ and that these differences in length of the paired regions are not correlated with the developmental stage of the nuclei. In 12 nuclei, the central region of the synaptonemal complex had not attained its normal structure (compare Figures 18 and 19). The two lateral components however were positioned $1100 \AA$ apart, a distance characteristic of completed complexes. In two nuclei, the $X$ and $Y$ chromosomes had their attachment sites on the nuclear envelope in proximity of each other but a central region could not be detected (Figure 20). The lateral components of the $\mathrm{X}$ and $\mathrm{Y}$ chromosomes were completely reconstructed in one of these nuclei (Figure 20) and the lengths of the lateral components calculated, the lengths of the $X$ and $Y$ chromosomes amounting to $9.4 \mu \mathrm{m}$ and $2.8 \mu \mathrm{m}$ respectively. The $\mathrm{X}$ and $\mathrm{Y}$ chromosomes each possessed two smaller heterochromatic regions, one of these possibly being the centromeric heterochromatin.

In the remaining nuclei, the lateral components of the $\mathrm{X}$ and $\mathrm{Y}$ chromosomes in the $\mathrm{XY}$ body appeared to be discontinuous and were branched at several locations (Figures 18 and 19). Complete reconstructions accounting for all lateral component segments in the XY body have not been possible. Compacted chromatin of the same density as the centromeric heterochromatin of the autosomes is present either inside the $X Y$ body or at its periphery (Figure 21), but the partial reconstructions failed to establish the relation between the lateral components of the $\mathrm{X}$ and $\mathrm{Y}$ chromosomes and the heterochromatin. 


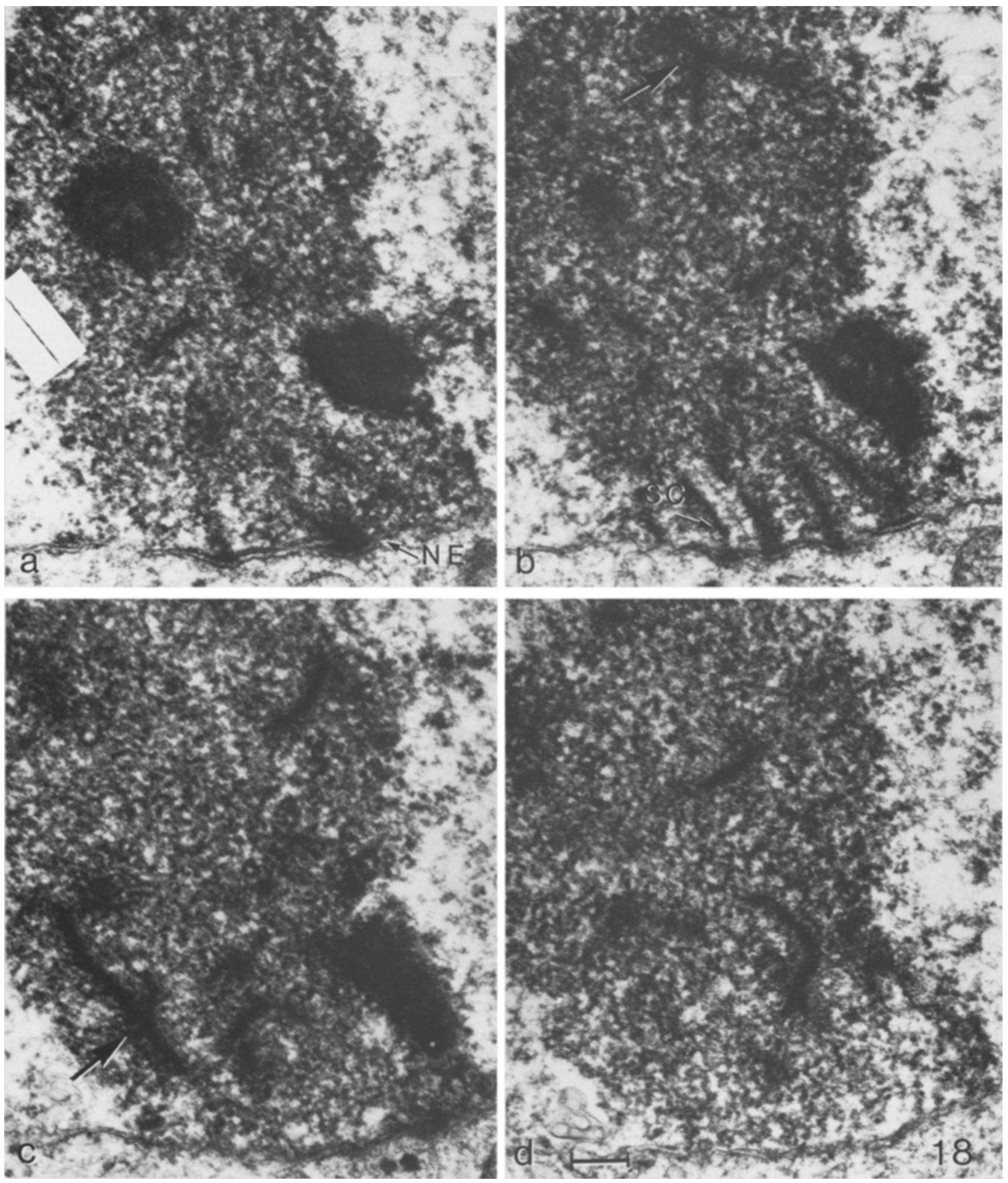

Figure 18. Four consecutive sections through the $\mathrm{XY}$ body of a pachytene spermatocyte. A piece of synaptonemal complex (SC) is attached to the nuclear envelope (NE) in Figure b. Arrows denote bifurcations of the lateral components. Two regions of material similar in electron density to the lateral components and the nucleoli are present in the $X Y$ body.

$(\mathrm{Bar}=0.2 \mu \mathrm{m})$ 

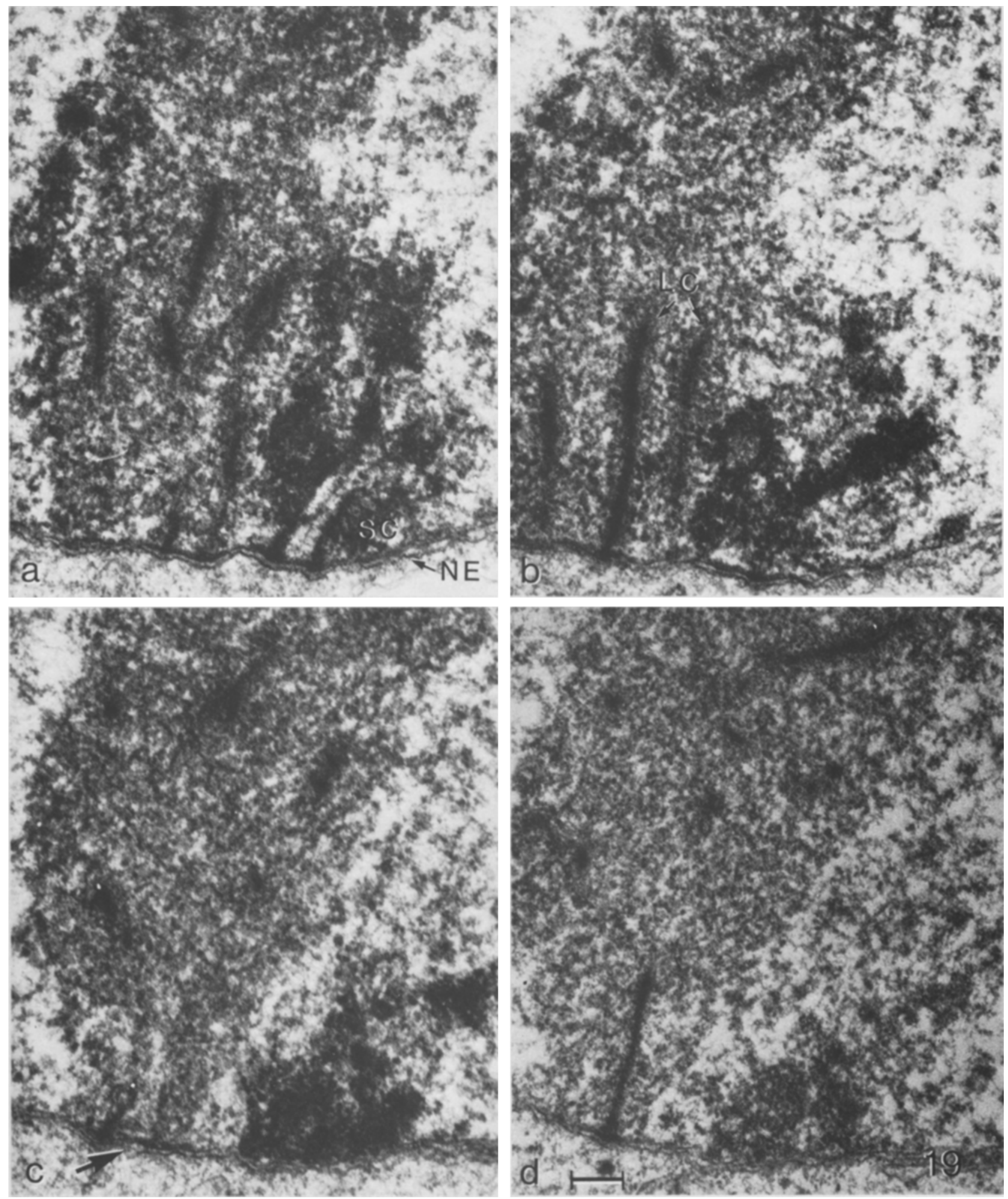

Figure 19. Four consecutive sections through an XY body at mid pachytene. The central region has not attained the ultrastructure characteristic of normal synaptonemal complexes (arrow). LC, lateral component, SC, synaptonemal complex of autosomal bivalent.

$(\mathrm{Bar}=0.2 \mu \mathrm{m})$ 
Table II

Morphology and length of the synaptonemal complex between the paired regions of the $X$ and $Y$ chromosomes.

\begin{tabular}{|c|c|c|c|}
\hline $\begin{array}{l}\text { Nucleus } \\
\text { number }\end{array}$ & $\begin{array}{c}\text { Stage in } \\
\text { pachytene }\end{array}$ & Central region & $\begin{array}{l}\text { Length of syn- } \\
\text { aptonemal } \\
\text { complex } \\
\text { between X and } \\
\text { Y chromo- } \\
\text { somes }(\mu \mathrm{m})\end{array}$ \\
\hline 10 & Early & - & - \\
\hline $\begin{array}{r}1 \\
3 \\
4 \\
20 \\
21\end{array}$ & $\begin{array}{c}\text { Early/mid } \\
- \\
- \\
- \\
-\end{array}$ & $\begin{array}{l}+++ \\
++ \\
+++ \\
++ \\
++\end{array}$ & $\begin{array}{l}0.3 \\
0.4 \\
0.4 \\
0.3 \\
0.3\end{array}$ \\
\hline $\begin{array}{r}2 \\
7 \\
9 \\
11 \\
12 \\
17 \\
18 \\
19 \\
22\end{array}$ & $\begin{array}{c}\text { Mid } \\
- \\
- \\
- \\
- \\
- \\
- \\
- \\
-\end{array}$ & $\begin{array}{l}++ \\
++ \\
+++ \\
++ \\
++ \\
0 \\
- \\
+++ \\
+++\end{array}$ & $\begin{array}{c}0.2 \\
0.1 \\
0.4 \\
0.4 \\
0.4 \\
- \\
- \\
0.5 \\
1.0\end{array}$ \\
\hline $\begin{array}{r}8 \\
13 \\
14 \\
15 \\
16\end{array}$ & $\begin{array}{c}\text { Mid/late } \\
- \\
- \\
- \\
-\end{array}$ & $\begin{array}{l}++ \\
++ \\
++ \\
++ \\
+++\end{array}$ & $\begin{array}{l}0.3 \\
0.2 \\
0.4 \\
0.2 \\
0.9\end{array}$ \\
\hline $\begin{array}{l}5 \\
6\end{array}$ & $\begin{array}{c}\text { Late } \\
-\end{array}$ & $\begin{array}{l}+++ \\
++\end{array}$ & $\begin{array}{l}0.7 \\
0.1\end{array}$ \\
\hline
\end{tabular}

+++ , normal. ++ , diffuse - , absent. 0 , no data.

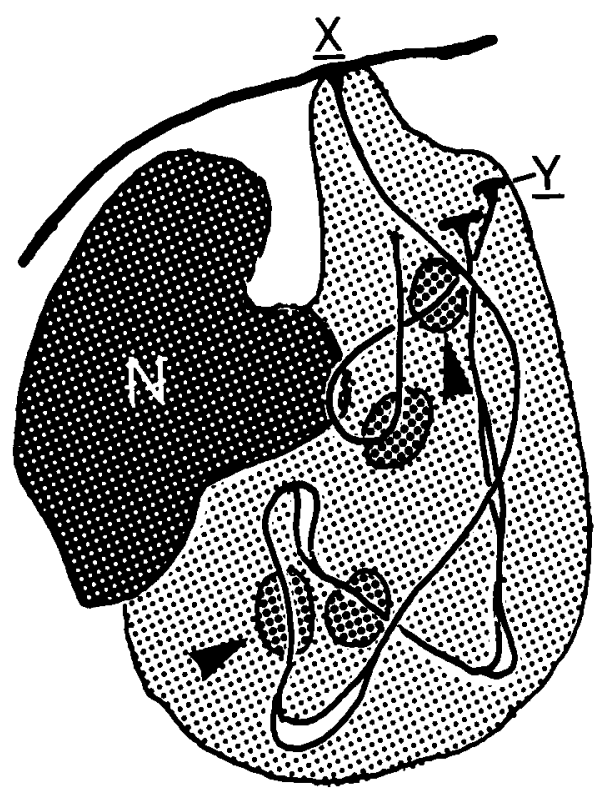

Figure 20. Reconstruction of the lateral components of the $\mathrm{X}$ and $\mathrm{Y}$ chromosomes. The possible position of the centromeric heterochromatin is denoted by arrows. In addition, each of the chromosomes has a heterochromatic knob. Three of the four telomeres are attached to the nuclear envelope and two of them, one on each chromosome, are located $300 \AA$ apart. The lateral component of the $\mathrm{X}$ chromosome is at several locations branched giving rise to short stretches of "double" lateral components. The lateral component lengths of the $\mathrm{X}$ and $\mathrm{Y}$ chromosomes are $9.4 \mu \mathrm{m}$ and $2.8 \mu \mathrm{m}$ respectively. The association of a major nucleolus to the $X Y$ body may either be the result of a fusion between a free nucleolus and the $X Y$ body or reflect the presence of a nucleolus organizer region on the $\mathrm{X}$ and $\mathrm{Y}$ chromosomes.

Figure 21. A complete reconstruction of a pachytene spermatocyte nucleus (number 9). An assembly of Golgi apparatuses and centrioles is present in the left part of the reconstruction. All 44 autosomes are paired into bivalents each with a continuous synaptonemal complex from telomere to telomere. The telomeres are attached to the nuclear envelope, the attachment sites being evenly distributed over the inner surface of the nucleus. The centromeric heterochromatin (red) of the acrocentric bivalents 15 and 22 has fused at the nuclear envelope. Note that the spherical nucleolus containing two dense bodies is lying free in the nucleoplasm. The bipartite centromeric heterochromatin of bivalents 1 and 9 has fused into a large body located in the central part of the nucleus while that of bivalent 16 is considerably smaller and is located in a different part of the nucleus. A small piece of synaptonemal complex is present in the $X Y$ body (upper part of the nucleus). The lateral components of the remainder of the $X$ and $Y$ chromosomes were discontinuous and could not be reconstructed. (The underlined numbers are the bivalent numbers. See also explanation to hatchings of Figures $21-23$ ) 
EXPLANATION TO HATCHINGS OF FIGURES $21-23$
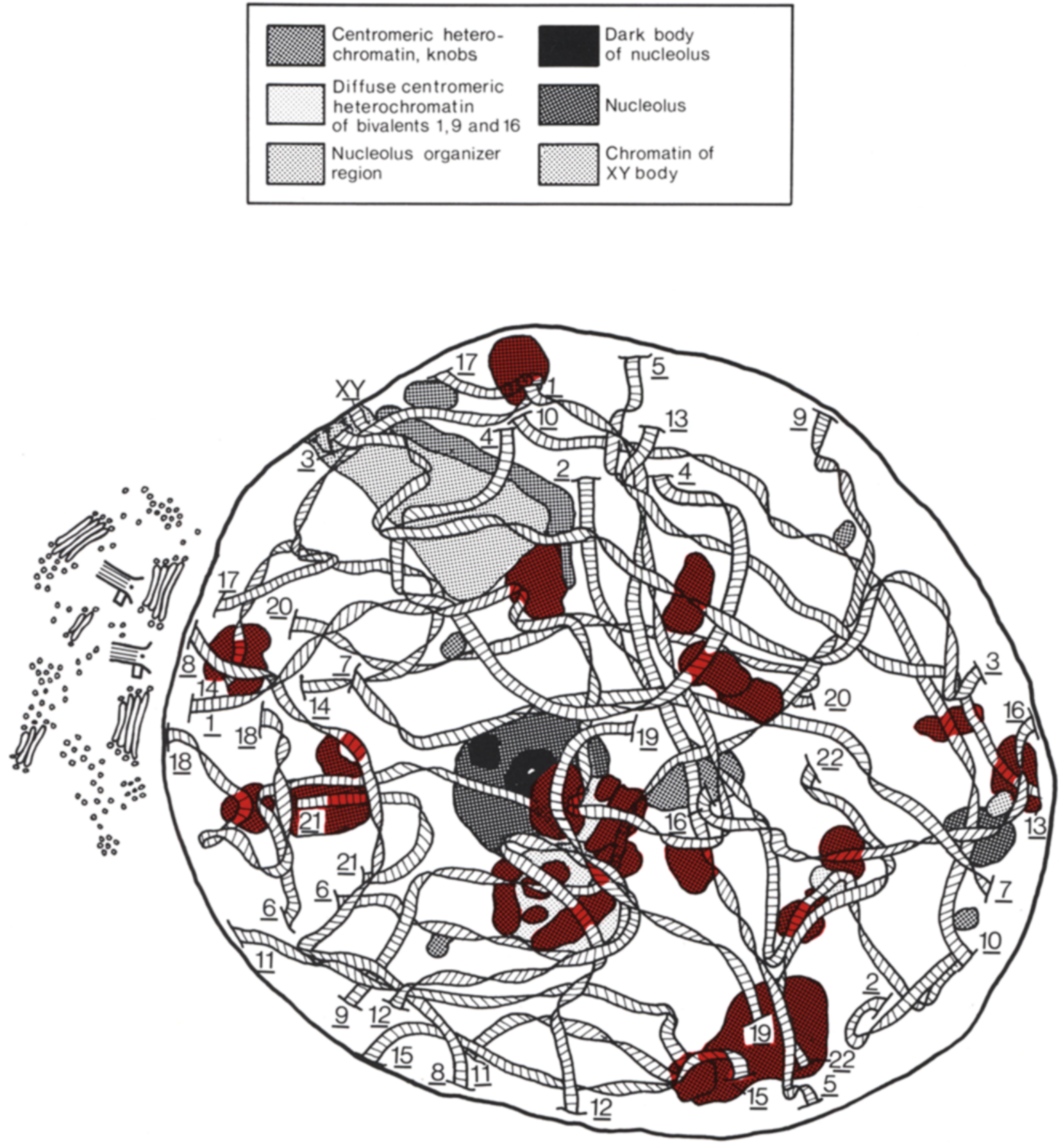
Table III

Total length of the autosomal synaptonemal complex complement for 22 nuclei from $\mathbf{5}$ human males.

\begin{tabular}{|c|c|c|c|c|}
\hline $\begin{array}{l}\text { Nucleus } \\
\text { number }\end{array}$ & $\begin{array}{c}\text { Case } \\
\text { number }\end{array}$ & $\begin{array}{l}\text { Stage in } \\
\text { pachytene }\end{array}$ & $\begin{array}{l}\text { Total length of } \\
\text { synaptonemal } \\
\text { complexes }(\mu \mathrm{m})\end{array}$ & $\begin{array}{c}\text { Mean total length of } \\
\text { synaptonemal complexes }(\mu \mathrm{m})\end{array}$ \\
\hline $\begin{array}{l}1 \\
2 \\
3 \\
4 \\
5 \\
6\end{array}$ & 1 & $\begin{array}{c}\text { Early/mid } \\
- \\
- \\
\text { Mid } \\
\text { Late } \\
-\end{array}$ & $\begin{array}{l}233 \\
257 \\
218 \\
233 \\
240 \\
237\end{array}$ & $236 \pm 13$ \\
\hline $\begin{array}{r}7 \\
8 \\
9 \\
10 \\
11 \\
12\end{array}$ & 2 & $\begin{array}{c}\text { Early } \\
\text { Mid } \\
- \\
- \\
- \\
\text { Mid/late }\end{array}$ & $\begin{array}{l}214 \\
256 \\
258 \\
222 \\
218 \\
251\end{array}$ & $235 \pm 19$ \\
\hline $\begin{array}{l}13 \\
14 \\
15\end{array}$ & 3 & $\begin{array}{c}\text { Mid/late } \\
- \\
-\end{array}$ & $\begin{array}{l}216 \\
228 \\
210\end{array}$ & $220 \pm 9$ \\
\hline $\begin{array}{l}16 \\
17 \\
18 \\
19\end{array}$ & 4 & $\begin{array}{c}\text { Mid } \\
- \\
- \\
\text { Mid/late }\end{array}$ & $\begin{array}{l}249 \\
199 \\
226 \\
243\end{array}$ & $229 \pm 22$ \\
\hline $\begin{array}{l}20 \\
21 \\
22\end{array}$ & 5 & $\begin{array}{c}\text { Early/mid } \\
- \\
\text { Mid }\end{array}$ & $\begin{array}{l}218 \\
226 \\
227\end{array}$ & $224 \pm 5$ \\
\hline
\end{tabular}

\subsection{The synaptonemal complex in pachytene nuclei}

\subsubsection{Total lengths per nucleus}

The total length per nucleus of all autosomal synaptonemal complexes is shown in Tables III and IV, in Table III arranged according to case number and in Table IV according to developmental stage of the nuclei. The total length varies among the 22 nuclei between 199 and 258 $\mu \mathrm{m}$ with an average value of $231 \pm 16 \mu \mathrm{m}$. As judged from t-test comparisons, the total lengths of autosomal synaptonemal complexes do not differ significantly among nuclei of different developmental stage or among nuclei from different individuals.

\subsubsection{Chriteria used in classification of pachytene bivalents}

The criteria used in the classification of the
22 autosomal bivalents are with the exception of bivalents 1,9, and 16 entirely based on relative lengths and centromere indices (CI $=$ length of the short arm $\times 100 /$ total length of the bivalent) and are comparable to those given by Hultén at the Paris Conference 1971 (38).

1) Bivalents 1 (group A), 9 (group C), and 16 (group D): These bivalents are identified by their bipartite centromeric heterochromatin, bivalent 9 having the largest segment of diffuse heterochromatin. Bivalent 1 is the longest and bivalent 16 the shortest of the three bivalents with diffuse heterochromatin.

2) Bivalents 2 and 3 (group A): Bivalent 3 is 
Table IV

Total length of the autosomal synaptonemal complex complement for 22 nuclei arranged according to substage of pachytene.

\begin{tabular}{|c|c|c|c|}
\hline $\begin{array}{c}\text { Nucleus } \\
\text { number }\end{array}$ & $\begin{array}{c}\text { Stage in } \\
\text { pachytene }\end{array}$ & $\begin{array}{c}\text { Total length of } \\
\text { synaptonemal } \\
\text { complexes }(\mu \mathrm{m})\end{array}$ & $\begin{array}{c}\text { Mean total } \\
\text { length of } \\
\text { complexes }(\mu \mathrm{m})\end{array}$ \\
\hline 10 & Early & 214 & 214 \\
\hline 1 & Early/mid & 233 & \\
3 & - & 257 & \\
4 & - & 218 & \\
20 & - & 218 & $230 \pm 16$ \\
21 & - & 226 & \\
\hline 2 & Mid & 233 & \\
7 & - & 256 & \\
9 & - & 258 & \\
11 & - & 222 & \\
12 & - & 218 & \\
17 & - & 249 & \\
18 & - & 199 & \\
19 & - & 226 & $232 \pm 19$ \\
22 & - & 227 & \\
\hline 8 & Mid/ate & 251 & \\
13 & - & 216 & \\
14 & - & 228 & \\
15 & - & 210 & $230 \pm 17$ \\
16 & - & 243 & \\
\hline 5 & Late & 238 & \\
6 & - & 237 & $238 \pm 1$ \\
\hline & & & \\
\hline 16 & & \\
\hline
\end{tabular}

almost metacentric and shorter than 2.

3) Bivalents 4 and 5 (group B): Bivalent 5 is longer than bivalent 4 .

4) Bivalents $6-8,10-12$ (group C): Bivalent 12 has the lowest centromere index. Bivalents 6-8, 10, and 11 are arranged according to decreasing length in the following way: 6,7 , 10,8 , and 11 . It should be noted that the cassification of bivalents in this group is somewhat ambiguous due to the similarity in lengths and centromere indices of the bivalents of the group.

5) Bivalents 13-15 (group D): This group consists of the largest acrocentric bivalents. They are arranged according to length as follows: 13 , 14 , and 15 .

6) Bivalents 17 and 18 (group E): Bivalent 17 is longer than 18.

7) Bivalents 19 and 20 (group F): Bivalent 20 is longer than 19.

8) Bivalents 21 and 22 (group G): The two shortest acrocentric bivalents, 22 being the longer one.

\subsubsection{The pachytene karyotype}

One the basis of the criteria described in the previous section and the definitions for the allocation of bivalents into group $A$ to $G$ given in the Denver Report (10) it was possible to identify unequivocally 14 of the 22 autosomal bivalents. Five of the remaining bivalents (numbers 6-8, 10, and 11 ) belong to the $\mathrm{C}$ group and the last three (numbers 13-15) to the D group (Figure 24). Due to the similarity in relative lengths and centromere indices, the ranking numbers assigned to members of groups $\mathrm{C}$ and $\mathrm{D}$ may represent different bivalents in different nuclei. The mean absolute and relative lengths and the centromere indices for the 22 autosomal bivalents from the 22 nuclei analyzed are given in Table $\mathrm{V}$ and examples of serial reconstructions of whole nuclei are presented in Figures 21 and 22.

\subsubsection{Comparison between the pachytene and diakinesis karyotype}

Figures 25 and 26 show a comparison between light microscopical data on bivalent lengths at diakinesis (26) and relative synaptonemal complex lengths and centromere indices at pachytene. A correlation coefficient of 0.97 for the relative lengths and of 0.91 for the centromere indices demonstrates that the classification of the pachytene bivalents corresponds very closely to that obtained from light microscopical data on relative lengths and centromere indices at diakinesis.

A more detailed comparison of light and electron microscopical data with a t-test has however revealed small but significant differences in relative lengths as well as in centromere indices. Thirteen of the 22 bivalents (numbers $2-5,7,9,14-17,19,20$, and 22) were 


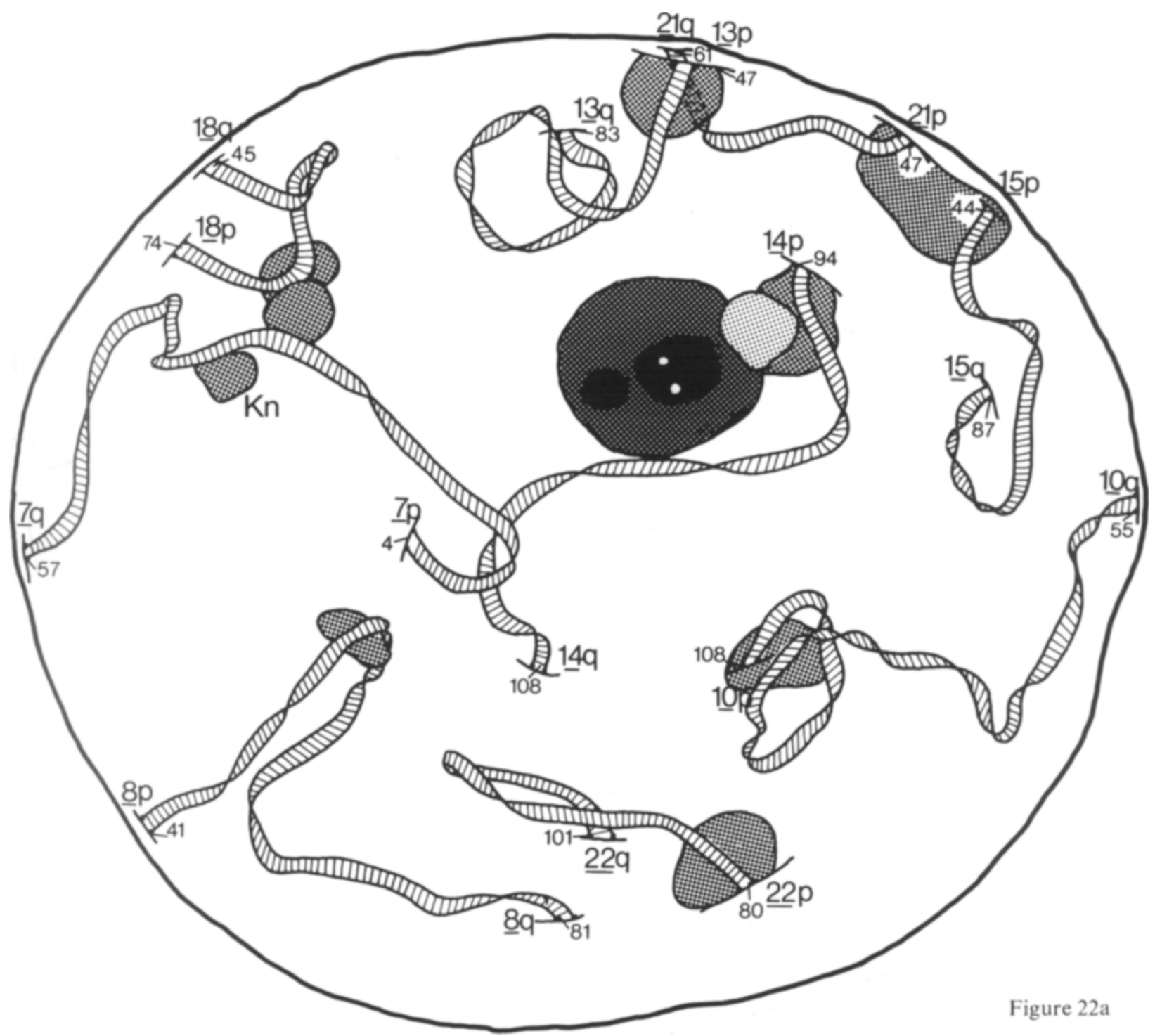

Figure 22. A complete reconstruction of a pachytene spermatocyte nucleus (number 7). A major nucleolus containing two highly electron scattering bodies is attached to the centromeric heterochromatin of bivalent 14 through a less electron dense filamentous region, compare with Figures 13, 15, 16, and 17. In Figure b, the XY body is present in the lower part of the nucleus. A short piece of synaptonemal complex is evident near the attachment sites of the lateral components on the nuclear envelope, but the central region has not attained its normal appearance. The bipartite centromeric heterochromatin of bivalents 1 and 9 has fused whereas that of bivalent 16 is located in a different region of the nucleus. It is evident in Figures $a, b$, and $c$ that all synaptonemal complexes are continuous between the attachment sites on the nuclear envelope and that the attachment sites are evenly distributed throughout the nuclear envelope. (The underlined numbers are the bivalent numbers, $p=$ short arm, $q=$ long arm. The small numbers indicate the number of the section in which the attachment site of a bivalent is included. See also explanation to hatchings of Figures 21-23). Kn, knob. 


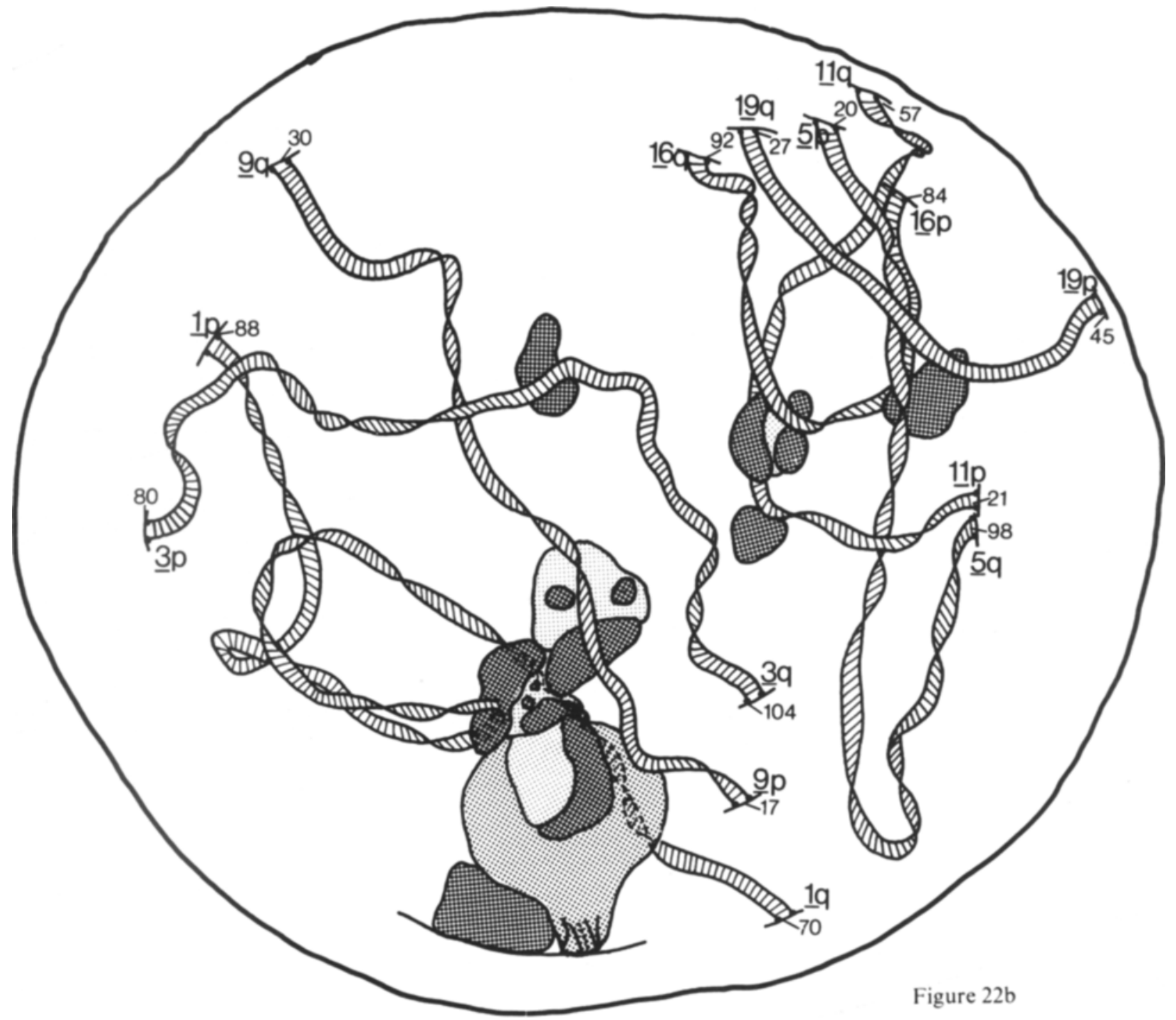

found to differ significantly in relative length while 5 bivalents (numbers 1, 5, 6, 8, and 19) showed significantly different centromere indices. The observed differences in relative length as seen in Figure 27 are distributed in a non-random way: The long diakinesis bivalents (numbers 1-5) are generally shorter at pachytene whereas the short diakinesis bivalents (numbers 16-22) are longer at pachytene. These observations suggest that a differential shortening takes place from pachytene to diakinesis. Alternatively, these differences may be the result of the different methods of preparation for light and electron microscopy.

\subsubsection{Variation in length of individual bivalents}

The error in length determination by the reconstruction is estimated to be less than 10 per cent, primarily due to variation in section thickness and microscope magnification. The absolute lengths, the relative lengths and the centromere indices of the synaptonemal complex for bivalent $1,9,16,2,3,21$, and 22 in all 22 


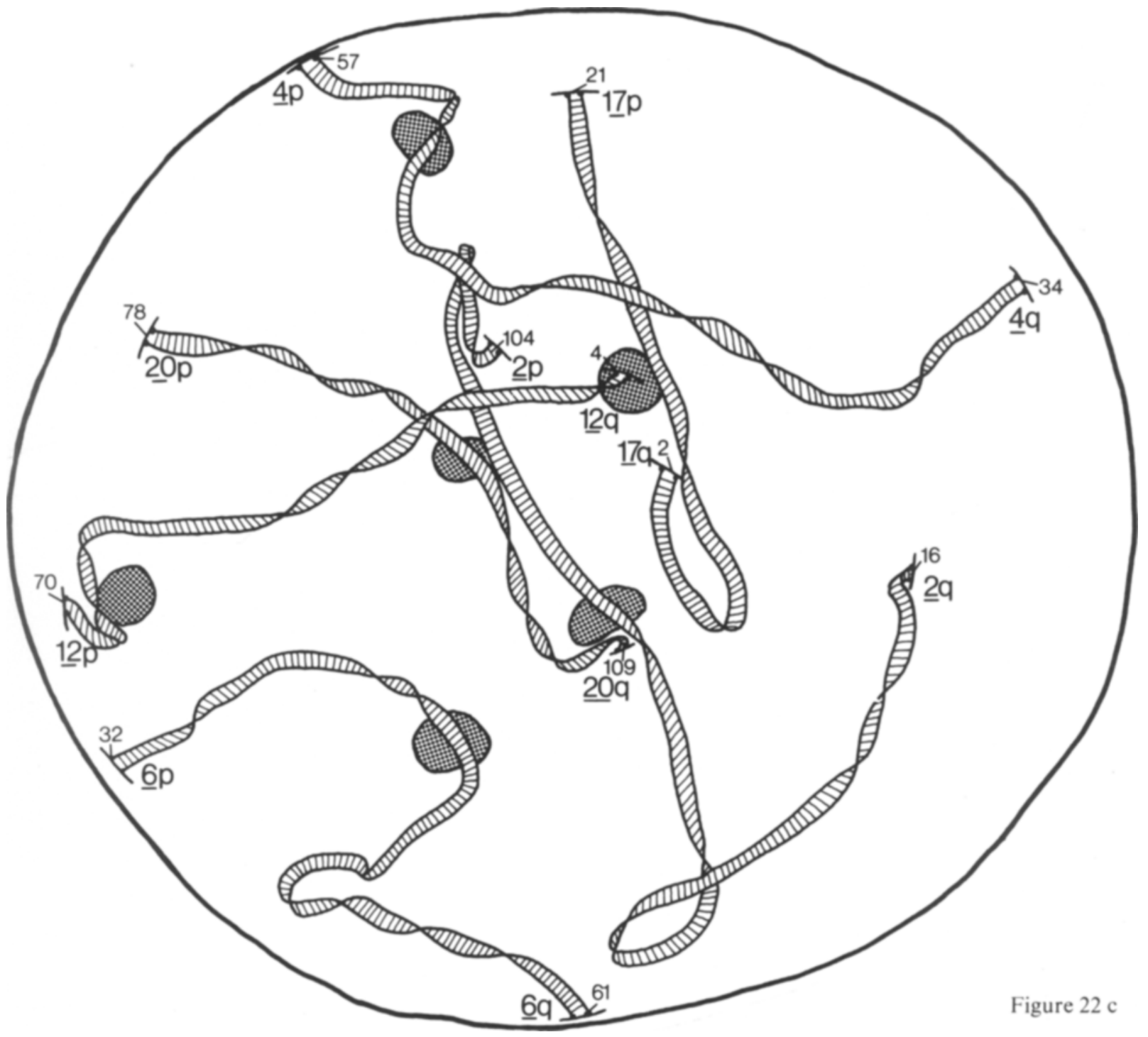

nuclei are presented in Tables VI to XII in order to permit an evaluation of the typical variations found. The variation of the absolute lengths is smallest in bivalent 1 with a standard deviation of $9.3 \%$ of the mean and largest in bivalents 9 and 22 with standard deviations amounting to $12.9 \%$ and $14.0 \%$ of the mean. The longest bivalent 9 measured $14.4 \mu \mathrm{m}$ and the shortest $9.6 \mu \mathrm{m}$. Such differences are considered to exceed significantly the variation caused by reconstruction and measuring in- accuracies. This variation is not due to variations between individuals, as only minor differences are found between the mean absolute bivalent lengths of the nuclei from each of the five individuals. (Figure 28). Thus, it is concluded that significant differences is absolute length of the synaptonemal complexes occur for a given bivalent among the meiocytes of a single individual.

Differences in relative synaptonemal complex length of individual bivalents among diffe- 


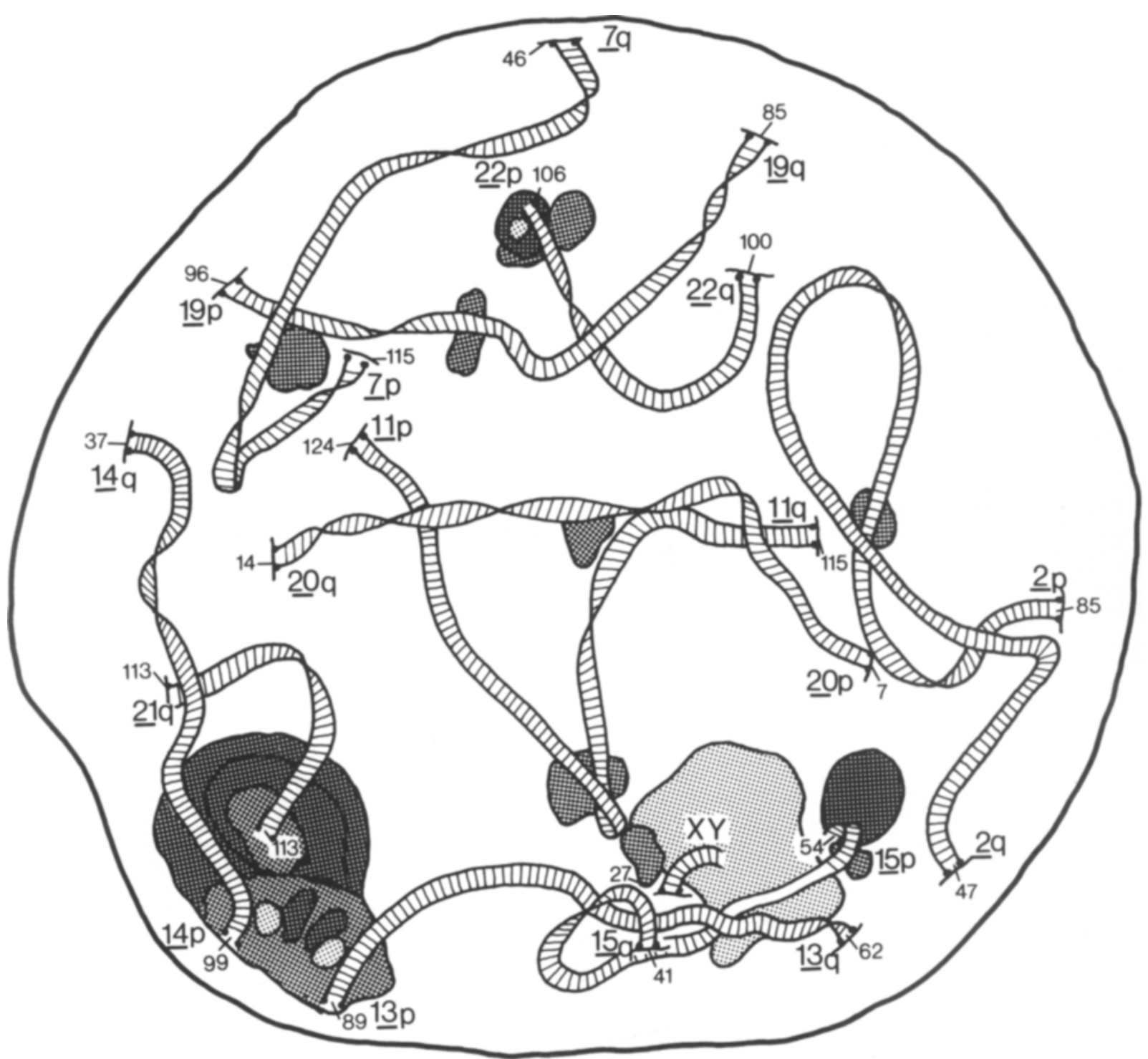

Figure 23. A portion of the reconstruction of a pachytene nucleus (number 5). All five acrocentric bivalents (1315,21 and 22) are involved in the organization of nucleoli. The centromeric heterochromatin of bivalents 13,14 , and 21 has fused and the three bivalents are all associated with the same major nucleolus. Bivalents 15 and 22 are each associated with a small nucleolus. The $X$ and $Y$ chromosomes are paired with a short piece of synaptonemal complex. Note that the central region of the complex is absent in the segment of bivalent 15 which is entrapped by the chromatin of the XY body, and that the telomeres of the short arms are free in the nucleoplasm.

rent nuclei tend to be smaller than the differences in absolute length (bivalents 1, 9, and 2). Thus the standard deviation of the relative length of bivalent 1 amounts to $4.5 \%$ of the mean compared to $9.3 \%$ for the absolute length. Standard deviations for the relative lengths of the complexes of bivalents $16,3,21$, and 22 are comparable to those for absolute 


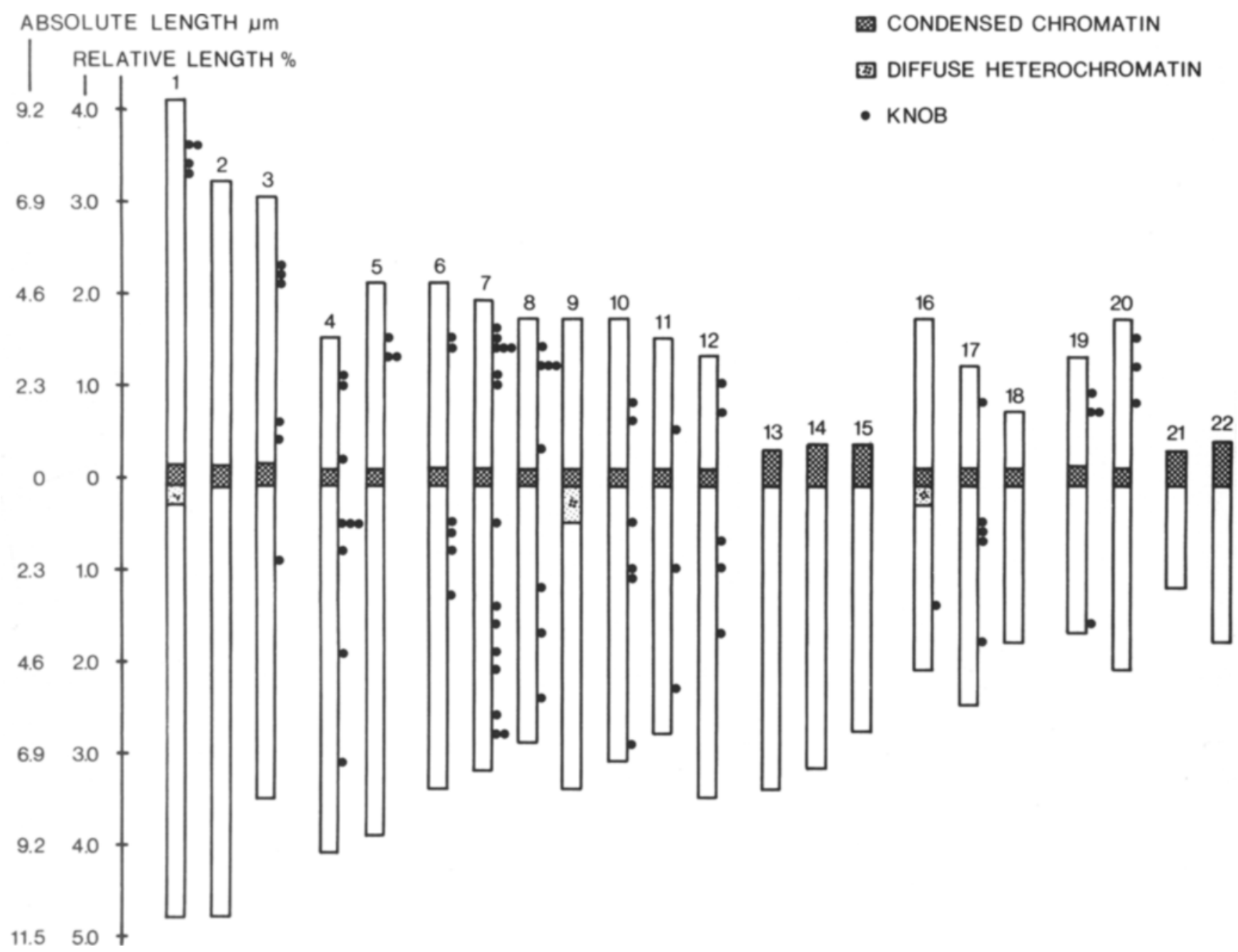

Figure 24. Idiogram showing the absolute and relative lengths of the synaptonemal complexes of the 22 autosomal bivalents. The position of the centromeric heterochromatin is indicated by the dark hatched area and the position of the diffuse heterochromatin of bivalents 1,9 , and 16 by a lighter hatching. The filled circles denote the position and the number of heterochomatic knobs. It is evident in the idiogram that the position and frequency of the knobs are highly variable. It should be noted though that knobs are absent on all acrocentric bivalents $(13-15,21$, and 22$)$ as well as on bivalents 2,9 , and 18 .

length. Differences in total synaptonemal complex length are distributed among several bivalents of a nucleus. Also the centromere indices of individual bivalents vary among different nuclei, the variation exceeding that attributable to errors in the reconstruction and measuring procedure.

HULTÉN (26) noted a considerable variation in length of the centromeric heterochromatin of bivalent 9 at diakinesis. The present study revealed only limited variation in the volume of the centromeric heterochromatin of bivalent 9 at pachytene. It is considered unlikely that this small variation can account for the heterogenity in the synaptonemal complex lengths of bivalent 9 . 
Table V

Mean absolute length, relative length, and centromere index for the 22 autosomal bivalents from 22 pachytene nuclei. s.d., standard deviation.

\begin{tabular}{|c|c|c|c|c|c|c|}
\hline $\begin{array}{c}\text { Chromosome } \\
\text { number }\end{array}$ & $\begin{array}{c}\text { Absolute } \\
\text { length }(\mu \mathrm{m})\end{array}$ & s.d. & $\begin{array}{c}\text { Relative } \\
\text { length }\end{array}$ & s.d. & $\begin{array}{c}\text { Centromere } \\
\text { index }\end{array}$ & s.d. \\
\hline 1 & 20.5 & 1.9 & 8.9 & 0.4 & 46 & 2 \\
2 & 18.5 & 2.0 & 8.0 & 0.5 & 40 & 3 \\
3 & 14.9 & 1.7 & 6.5 & 0.6 & 47 & 3 \\
\hline 4 & 13.0 & 1.3 & 5.6 & 0.4 & 26 & 3 \\
5 & 13.7 & 1.5 & 6.0 & 0.4 & 35 & 6 \\
\hline 6 & 12.8 & 1.1 & 5.5 & 0.3 & 38 & 4 \\
7 & 11.7 & 1.0 & 5.1 & 0.2 & 37 & 4 \\
8 & 10.6 & 0.9 & 4.6 & 0.2 & 36 & 5 \\
10 & 11.6 & 1.5 & 5.1 & 0.4 & 33 & 4 \\
11 & 11.2 & 1.0 & 4.8 & 0.2 & 35 & 5 \\
12 & 10.0 & 1.0 & 4.3 & 0.3 & 35 & 3 \\
\hline 13 & 11.1 & 1.2 & 4.8 & 0.4 & 27 & - \\
14 & 8.5 & 0.5 & 3.7 & 0.2 & 8 & - \\
15 & 7.9 & 0.6 & 3.5 & 0.2 & 10 & - \\
\hline 16 & 7.2 & 0.8 & 3.1 & 0.3 & 11 & 4 \\
17 & 8.9 & 1.0 & 3.8 & 0.4 & 46 & 5 \\
18 & 8.6 & 1.8 & 3.7 & 0.8 & 32 & 5 \\
\hline 19 & 5.8 & 0.8 & 2.5 & 0.2 & 29 & 4 \\
\hline 20 & 6.8 & 1.3 & 3.0 & 0.5 & 43 & 4 \\
\hline 21 & 8.8 & 1.2 & 3.8 & 0.4 & 44 & 20 \\
\hline 22 & 3.5 & 0.4 & 1.5 & 0.2 & 18 & - \\
\hline
\end{tabular}

\subsubsection{Abnormal synaptonemal complexes}

A total of 9 bivalents with aberrant synaptonemal complexes have been found in the 22 nuclei analyzed. In four nuclei, one arm of a bivalent was trapped within the XY body. The trapped regions of the bivalents were either devoid of a central region of the synaptonemal complex or the central region was only associated with one of the lateral components (Figure 29). In two cases, one arm of a bivalent was not attached to the nuclear envelope. In one of them the short arm of bivalent 15 ended free in the nucleoplasm (Figure 23). In the other, the central region and one of the lateral components of the distal portion of the short arm of chromosome 1 were absent, a single unpaired lateral component extending about $1 \mu \mathrm{m}$ beyond the termination site of the central re- gion (Figure 30). In nucleus 14, the lateral components of the short arm and the centromeric region of chromosome 13 were separated by a distance of 6-700 $\AA$ but without a morphologically distinguishable central region. The centromeric heterochromatin was decondensed and the short arm was associated with a nucleolus of the early pachytene type.

Finally, it should by noted that in two cases, synaptonemal complexes of two bivalents were associated. In one case, the complexes of bivalents 2 and 3 shared a lateral component over a short distance whereas in the other case, exchange of pairing partner appeared to have occurred between chromosomes 3 and 5 , the two chromosomes being non-homologously paired over a distance of $0.2 \mu \mathrm{m}$. 


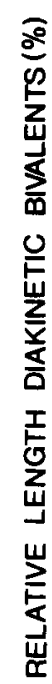

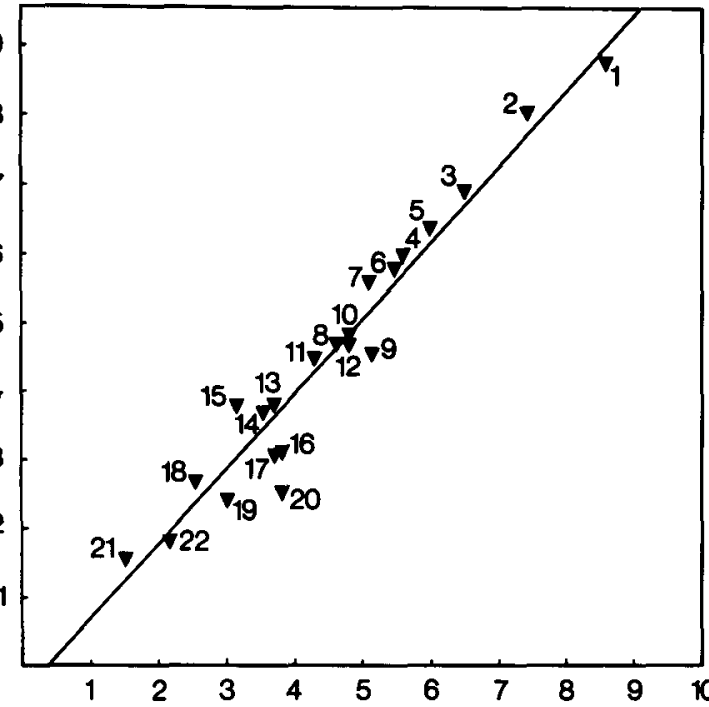

RELATIVE SYNAPTONEMAL COMPLEX LENGTH (\%)

Figure 25. A comparison between the mean relative bivalent lengths at diakinesis (26) and mean relative synaptonemal complex lengths of pachytene bivalents. The relative lengths are expressed as percentages of the total length of autosomal bivalents. The regression equation is $\mathrm{y}=1.09 \mathrm{x}-0.42$ and the correlation coefficient 0.97 .

RELATIVE LENGTH \%

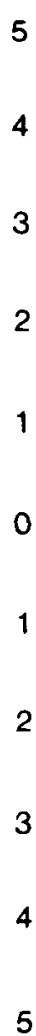

2
1

.
2

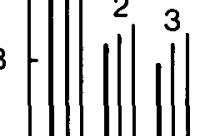

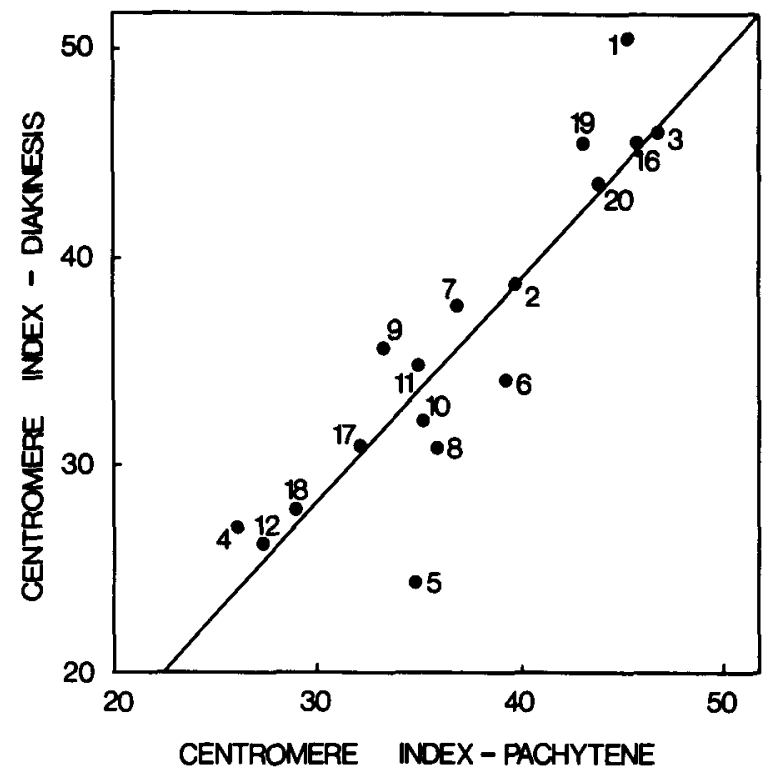

Figure 26. A comparison of centromere indices (length of the short arm x 100/total bivalent length) of bivalents at pachytene and diakinesis (26). The centromere indices of the acrocentric bivalents (1315,21 , and 22) are not included in the diagram due to the ambiguity in the determination of the short arm length of these bivalents. The regression equation is $y=1.12 x-5.39$ and the correlation coefficient 0.91 .
11

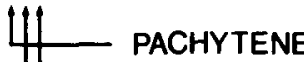

DIAKINESIS

SOMATIC METAPHASE

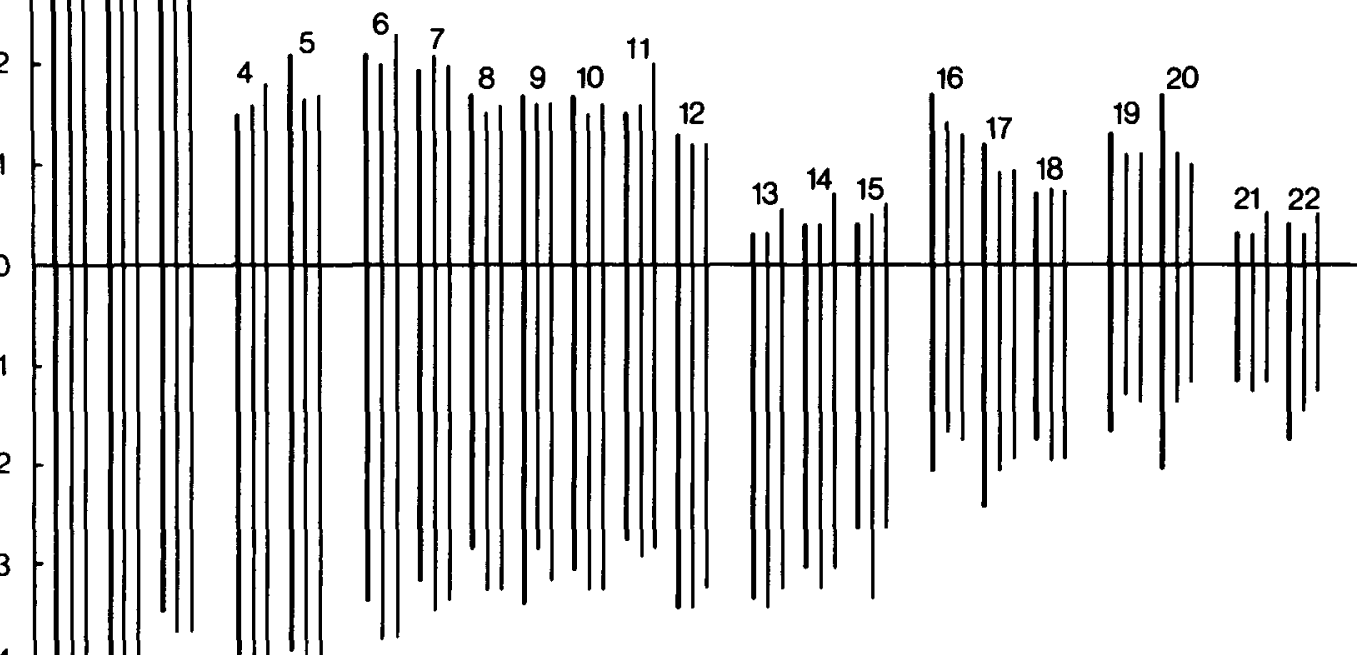


Table VI

Synaptonemal complex length and centromere index for bivalent 1.

\begin{tabular}{|c|c|c|c|}
\hline $\begin{array}{c}\text { Nucleus } \\
\text { number }\end{array}$ & $\begin{array}{c}\text { Absolute } \\
\text { length }(\mu \mathrm{m})\end{array}$ & $\begin{array}{c}\text { Relative } \\
\text { length }\end{array}$ & $\begin{array}{c}\text { Centromere } \\
\text { index }\end{array}$ \\
\hline 1 & 20.7 & 8.9 & 45 \\
2 & 20.3 & 8.7 & 49 \\
3 & 23.7 & 9.2 & 46 \\
4 & 20.6 & 9.4 & 43 \\
5 & 19.5 & 8.2 & 46 \\
6 & 20.8 & 8.8 & 44 \\
7 & 23.6 & 9.2 & 42 \\
8 & 22.8 & 9.1 & 47 \\
9 & 23.3 & 9.1 & 43 \\
10 & 18.6 & 8.7 & 48 \\
11 & 20.4 & 9.2 & 43 \\
12 & 19.6 & 9.0 & 45 \\
13 & 19.5 & 9.0 & 47 \\
14 & 18.5 & 8.1 & 42 \\
15 & 19.1 & 9.1 & 45 \\
16 & 21.8 & 9.0 & 49 \\
17 & 21.9 & 8.4 & 45 \\
18 & 16.3 & 9.3 & 45 \\
19 & 21.0 & 9.3 & 48 \\
20 & 18.5 & 8.5 & 48 \\
21 & 19.8 & 8.7 & 47 \\
22 & 19.6 & 8.7 & 47 \\
\hline Mean & $20.5 \pm 1.9$ & $8.9 \pm 0.4$ & $46 \pm 2$ \\
\hline
\end{tabular}

\section{DISCUSSION}

\subsection{The substages of pachytene}

The 22 pachytene nuclei have been arranged into a temporal sequence by degree of chromatin condensation, assuming a progressive condensation between zygotene and diplotene. As other cellular and nuclear characters have not proven useful in the subdivision of the pachytene stage, the temporal sequence of the nuclei is somewhat
Table VII

Synaptonemal complex and centromere index for bivalent 9.

\begin{tabular}{|c|c|c|c|}
\hline $\begin{array}{c}\text { Nucleus } \\
\text { number }\end{array}$ & $\begin{array}{c}\text { Absolute } \\
\text { length }(\mu \mathrm{m})\end{array}$ & $\begin{array}{c}\text { Relative } \\
\text { length }\end{array}$ & $\begin{array}{c}\text { Centromere } \\
\text { index }\end{array}$ \\
\hline 1 & 14.4 & 6.2 & 38 \\
2 & 10.9 & 4.7 & 36 \\
3 & 13.4 & 5.2 & 38 \\
4 & 10.8 & 5.0 & 29 \\
5 & 13.1 & 5.5 & 34 \\
6 & 11.2 & 4.7 & 35 \\
7 & 11.9 & 4.7 & 33 \\
8 & 13.0 & 5.2 & 30 \\
9 & 14.9 & 5.8 & 34 \\
10 & 10.1 & 4.7 & 33 \\
11 & 12.4 & 5.6 & 38 \\
12 & 10.7 & 4.9 & 36 \\
13 & 10.4 & 4.8 & 30 \\
14 & 9.9 & 4.4 & 28 \\
15 & 11.4 & 5.4 & 34 \\
16 & 12.0 & 5.0 & 30 \\
17 & 12.6 & 5.1 & 31 \\
18 & 9.6 & 4.9 & 31 \\
19 & 10.5 & 4.6 & 33 \\
20 & 10.9 & 5.0 & 41 \\
21 & 10.5 & 4.6 & 32 \\
22 & 10.8 & 4.8 & 29 \\
\hline Mean & $11.6 \pm 1.5$ & $5.1 \pm 0.4$ & $33 \pm 4$ \\
\hline
\end{tabular}

ambiguous. Preliminary observations have however indicated that the chromatin is uncondensed at late zygotene and that the chromatin of diplotene bivalents is heavily compacted (HOLM and RASMUSSEN, unpublished observations). Earlier studies on meiosis in mouse $(46,47)$ and man $(48,51)$ have suggested the reverse pattern: The chromatin was considered to be condensed at the onset of pachytene and to be progressively uncondensed

Figure 27. A comparison between mean relative chromosome lengths at pachytene, diakinesis and at somatic metaphase (26). Twenty-two nuclei were analyzed at pachytene, between 11 and 41 at diakinesis, and 10 at somatic metaphase. The diagram shows that the differences in relative lengths are distributed in a non-random way among the bivalents: The longer chromosomes (1-5) are generally shorter at pachytene than at diakinesis and somatic metaphase whereas the opposite situation is encountered for the smaller chromosomes (16-22). The relative lengths of the medium sized chromosomes (6-15) in pachytene, diakinesis, and somatic metaphase are very similar. 
Synaptonemal complex length and centromere index for bivalent 16 .

\begin{tabular}{|c|c|c|c|}
\hline $\begin{array}{c}\text { Nucleus } \\
\text { number }\end{array}$ & $\begin{array}{c}\text { Absolute } \\
\text { length }(\mu \mathrm{m})\end{array}$ & $\begin{array}{c}\text { Relative } \\
\text { length }\end{array}$ & $\begin{array}{c}\text { Centromere } \\
\text { index }\end{array}$ \\
\hline 1 & 11.5 & 4.8 & 38 \\
2 & 8.5 & 3.6 & 45 \\
3 & 9.6 & 3.6 & 48 \\
4 & 8.4 & 3.9 & 38 \\
5 & 10.1 & 4.2 & 49 \\
6 & 10.0 & 4.2 & 42 \\
7 & 9.1 & 3.6 & 47 \\
8 & 9.3 & 3.7 & 48 \\
9 & 9.4 & 3.7 & 46 \\
10 & 8.3 & 3.9 & 39 \\
11 & 8.9 & 4.0 & 47 \\
12 & 7.7 & 3.5 & 47 \\
13 & 7.5 & 3.5 & 44 \\
14 & 8.9 & 3.9 & 46 \\
15 & 8.3 & 4.0 & 48 \\
16 & 9.3 & 3.8 & 46 \\
17 & 9.4 & 3.8 & 49 \\
18 & 8.0 & 4.1 & 46 \\
19 & 8.2 & 3.6 & 50 \\
20 & 9.8 & 4.5 & 39 \\
21 & 6.8 & 3.0 & 48 \\
22 & 7.8 & 3.5 & 48 \\
\hline Mean & $8.9 \pm 1.0$ & $3.8 \pm 0.4$ & $46 \pm 4$ \\
\hline
\end{tabular}

Table X

Synaptonemal complex length and centromere index for bivalent 3.

\begin{tabular}{|c|c|c|c|}
\hline $\begin{array}{c}\text { Nucleus } \\
\text { number }\end{array}$ & $\begin{array}{c}\text { Absolute } \\
\text { length }(\mu \mathrm{m})\end{array}$ & $\begin{array}{c}\text { Relative } \\
\text { length }\end{array}$ & $\begin{array}{c}\text { Centromere } \\
\text { index }\end{array}$ \\
\hline 1 & 13.6 & 5.8 & 45 \\
2 & 12.8 & 5.5 & 47 \\
3 & 17.1 & 6.7 & 50 \\
4 & 13.2 & 6.1 & 41 \\
5 & 15.1 & 6.3 & 46 \\
6 & 15.9 & 6.7 & 48 \\
7 & 16.7 & 6.5 & 50 \\
8 & 15.8 & 6.3 & 48 \\
9 & 16.5 & 6.4 & 50 \\
10 & 13.8 & 6.4 & 50 \\
11 & 17.4 & 7.8 & 48 \\
12 & 13.7 & 6.3 & 45 \\
13 & 12.5 & 5.8 & 48 \\
14 & 16.5 & 7.3 & 45 \\
15 & 12.0 & 5.7 & 50 \\
16 & 15.5 & 6.4 & 45 \\
17 & 17.3 & 7.0 & 50 \\
18 & 12.8 & 6.6 & 49 \\
19 & 15.7 & 6.9 & 44 \\
20 & 13.6 & 6.3 & 44 \\
21 & 14.8 & 6.6 & 47 \\
22 & 16.2 & 7.2 & 45 \\
\hline mean & $14.9 \pm 1.7$ & $6.5 \pm 0.6$ & $47+3$ \\
\hline
\end{tabular}

Synaptonemal complex length and centromere index for bivalent 2 .

\begin{tabular}{|c|c|c|c|}
\hline $\begin{array}{c}\text { Nucleus } \\
\text { number }\end{array}$ & $\begin{array}{c}\text { Absolute } \\
\text { length }(\mu \mathrm{m})\end{array}$ & $\begin{array}{c}\text { Relative } \\
\text { length }\end{array}$ & $\begin{array}{c}\text { Centromere } \\
\text { index }\end{array}$ \\
\hline 1 & 21.9 & 9.4 & 36 \\
2 & 18.6 & 8.0 & 37 \\
3 & 19.7 & 7.7 & 41 \\
4 & 17.6 & 8.1 & 41 \\
5 & 20.3 & 8.5 & 38 \\
6 & 19.0 & 8.0 & 42 \\
7 & 19.9 & 7.8 & 39 \\
8 & 20.1 & 8.0 & 40 \\
9 & 21.1 & 8.2 & 42 \\
10 & 16.9 & 7.9 & 39 \\
11 & 15.0 & 6.7 & 44 \\
12 & 17.6 & 8.1 & 40 \\
13 & 17.7 & 8.2 & 39 \\
14 & 17.6 & 7.8 & 38 \\
15 & 16.3 & 7.8 & 39 \\
16 & 21.9 & 9.0 & 40 \\
17 & 18.8 & 7.6 & 44 \\
18 & 14.3 & 7.3 & 33 \\
19 & 17.6 & 7.8 & 42 \\
20 & 17.9 & 8.2 & 41 \\
21 & 18.1 & 8.0 & 40 \\
22 & 18.2 & 8.0 & 40 \\
\hline Mean & $18.5 \pm 2.0$ & $8.0 \pm 0.5$ & $40 \pm 3$ \\
\hline
\end{tabular}

Table XI

Synaptonemal complex length and centromere index for bivalent 21 .

\begin{tabular}{|c|c|c|c|}
\hline $\begin{array}{c}\text { Nucleus } \\
\text { number }\end{array}$ & $\begin{array}{c}\text { Absolute } \\
\text { length }(\mu \mathrm{m})\end{array}$ & $\begin{array}{c}\text { Relative } \\
\text { length }\end{array}$ & $\begin{array}{c}\text { Centromere } \\
\text { index }\end{array}$ \\
\hline 1 & 3.7 & 1.6 & - \\
2 & 3.2 & 1.4 & - \\
3 & 4.5 & 1.7 & - \\
4 & 2.7 & 1.2 & - \\
5 & 3.8 & 1.6 & - \\
6 & 3.6 & 1.5 & - \\
7 & 4.1 & 1.6 & - \\
8 & 3.8 & 1.5 & - \\
9 & 3.1 & 1.2 & - \\
10 & 3.0 & 1.4 & 20 \\
11 & 3.2 & 1.4 & - \\
12 & 3.8 & 1.7 & - \\
13 & 3.1 & 1.4 & - \\
14 & 3.7 & 1.6 & - \\
15 & 3.4 & 1.6 & - \\
16 & 3.3 & 1.4 & - \\
17 & 3.3 & 1.3 & - \\
18 & 3.2 & 1.6 & - \\
19 & 3.6 & 1.6 & - \\
20 & 3.8 & 1.7 & - \\
21 & 3.6 & 1.6 & - \\
22 & 3.6 & 1.6 & - \\
\hline Mean & $3.5 \pm 0.4$ & $1.5 \pm 0.2$ & \\
\hline
\end{tabular}


Synaptonemal complex length and centromere index for bivalent 22 .

\begin{tabular}{|c|c|c|c|}
\hline $\begin{array}{l}\text { Nucleus } \\
\text { number }\end{array}$ & $\begin{array}{c}\text { Absolute } \\
\text { length }(\mu \mathrm{m})\end{array}$ & $\begin{array}{l}\text { Relative } \\
\text { length }\end{array}$ & $\begin{array}{c}\text { Centromere } \\
\text { index }\end{array}$ \\
\hline 1 & 4.4 & 1.9 & - \\
\hline 2 & 5.4 & 2.3 & - \\
\hline 3 & 5.4 & 2.1 & - \\
\hline 4 & 4.5 & 2.1 & - \\
\hline 5 & 4.5 & 1.9 & - \\
\hline 6 & 4.3 & 1.8 & - \\
\hline 7 & 6.9 & 2.7 & - \\
\hline 8 & 4.6 & 1.8 & - \\
\hline 9 & 6.6 & 2.6 & - \\
\hline 10 & 5.0 & 2.3 & 18 \\
\hline 11 & 5.6 & 2.5 & - \\
\hline 12 & 4.7 & 2.2 & - \\
\hline 13 & 4.5 & 2.1 & - \\
\hline 14 & 4.7 & 2.1 & - \\
\hline 15 & 5.1 & 2.4 & - \\
\hline 16 & 4.6 & 1.9 & - \\
\hline 17 & 4.3 & 1.7 & - \\
\hline 18 & 4.7 & 2.4 & - \\
\hline 19 & 5.4 & 2.4 & - \\
\hline 20 & 4.4 & 2.0 & - \\
\hline 21 & 5.2 & 2.3 & - \\
\hline 22 & 6.1 & 2.7 & - \\
\hline Mean & $5.0 \pm 0.7$ & $2.2 \pm 0.3$ & \\
\hline
\end{tabular}

during pachytene. The decondensation is believed to reach its maximum in the diffuse diplotene stage and to be followed by a condensed diplotene stage (51). Further investigations are necessary before the various meiotic substages described can be fitted into an unequivocal temporal sequence.

\subsection{Centromeric heterochromatin}

The present study has demonstrated that the centromere region of human chromosomes seen in the light microscope has its counterpart in the precociously condensed centromeric heterochromatin of the pachytene bivalents. The presence of one major body of heavily compacted chromatin per bivalent and the in terpretation of this body as the centromeric heterochromatin is in agreement with the results obtained with $\mathrm{C}$ banding techniques. These techniques have demonstrated that in somatic metaphase chromosomes as well as in diakinesis bivalents, $\mathrm{C}$ bands are present in the centromeric region, i.e. at the primary constriction (26).
The centromeric heterochromatin of bivalent 1, 9, and 16 has previously been organization. The large body of compacted chromatin marks the position of the centromere and the spherical body of compacted and diffuse chromatin extending into the long arm is presumably equivalent to the so-called secondary constriction of these chromosomes as seen in the light microscope. The mixture of condensed and diffuse chromatin characteristic of the centromeric heterochromatin of bivalents 1,9 , and 16 has previously been described for bivalent 9 by HUNGERFORD et al. (29) and GAGNÉ et al. (14) in light and electron microscope analyses of pachytene nuclei. The ultrastructure of the centromeric heterochromatin of bivalents 1,9 , and 16 is identical and in situ hybridization experiments have shown that the four satellite DNA's isolated from the human genome are predominantly confined to the diffuse heterochromatin of these chromosomes (21). The heteromorphism of these regions may somehow be related to the high redundancy of the satellite DNA's.

\subsection{Nucleoli and secondary constrictions}

The present investigation has unequivocally demonstrated that all 5 acrocentric bivalents are capable of organizing a nucleolus. This observation is in agreement with light microscopical observations by FERGUSON-SMITH (13) who noted associations between acrocentric bivalents and nucleoli in pachytene spermatocytes. Moreover, in situ hybridization experiments have shown that rRNA hybridizes specifically to the secondary constriction of all acrocentric bivalents $(12,23)$.

The centromeric heterochromatin of the acrocentric bivalents extends to the attachment sites of the short arms on the nuclear envelope. It was therefore not possible to identify the secondary constrictions or satellites as such. The absence of a distinct nucleolus organizer region in human spermatocytes may be due to the fact that the diploid genome only contains 420 cistrons coding for ribosomal RNA (3).

The change in nucleolar morphology during the course of pachytene and the observation that the nucleoli frequently detach from the bivalents are probably related to the decrease 


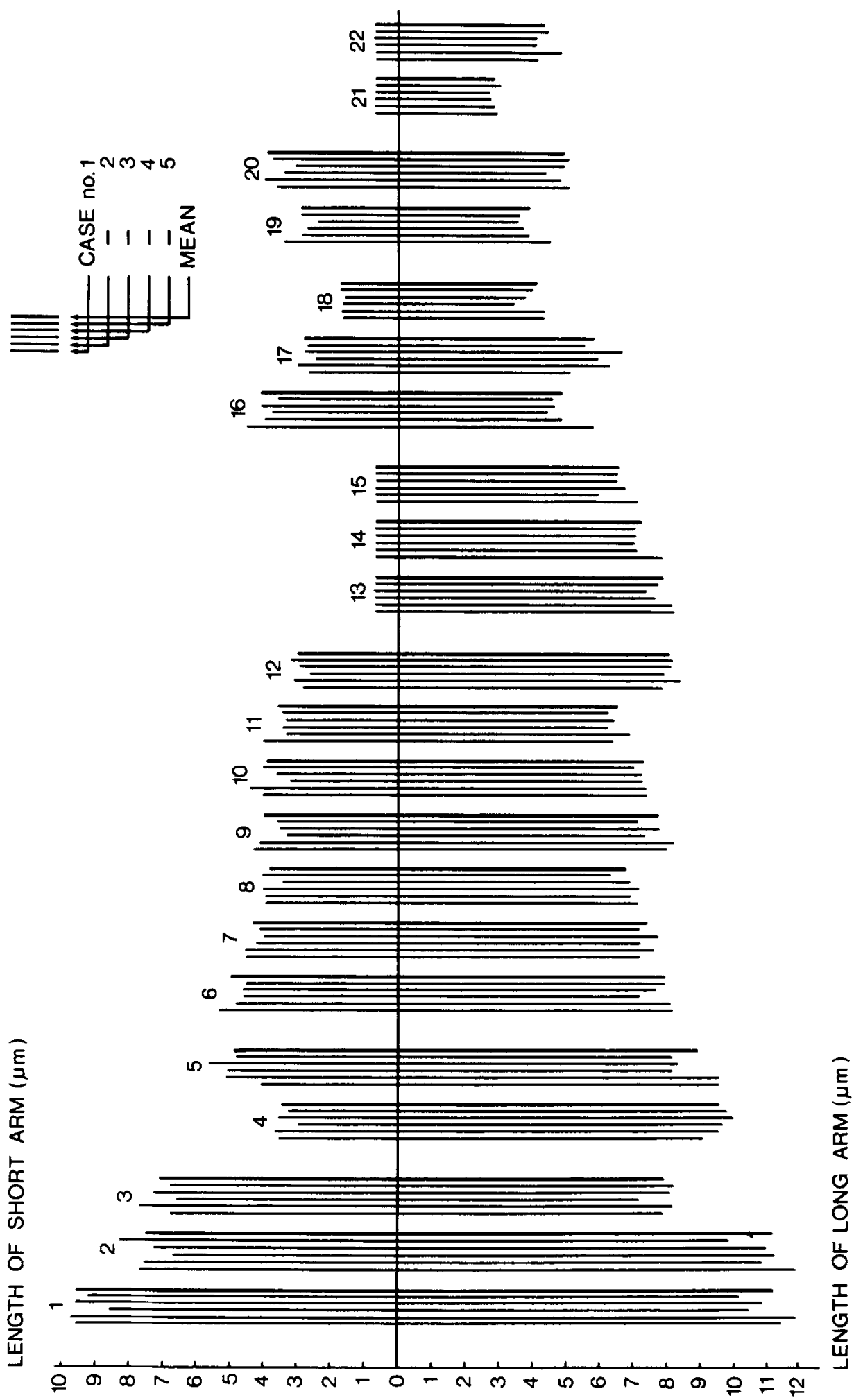

Figure 28. Mean absolute lengths of the 22 autosomal bivalents from each of the five individuals analyzed. Compare with Table III. Note the similarity in bivalent lengths and centromere indices among the five individuals. 


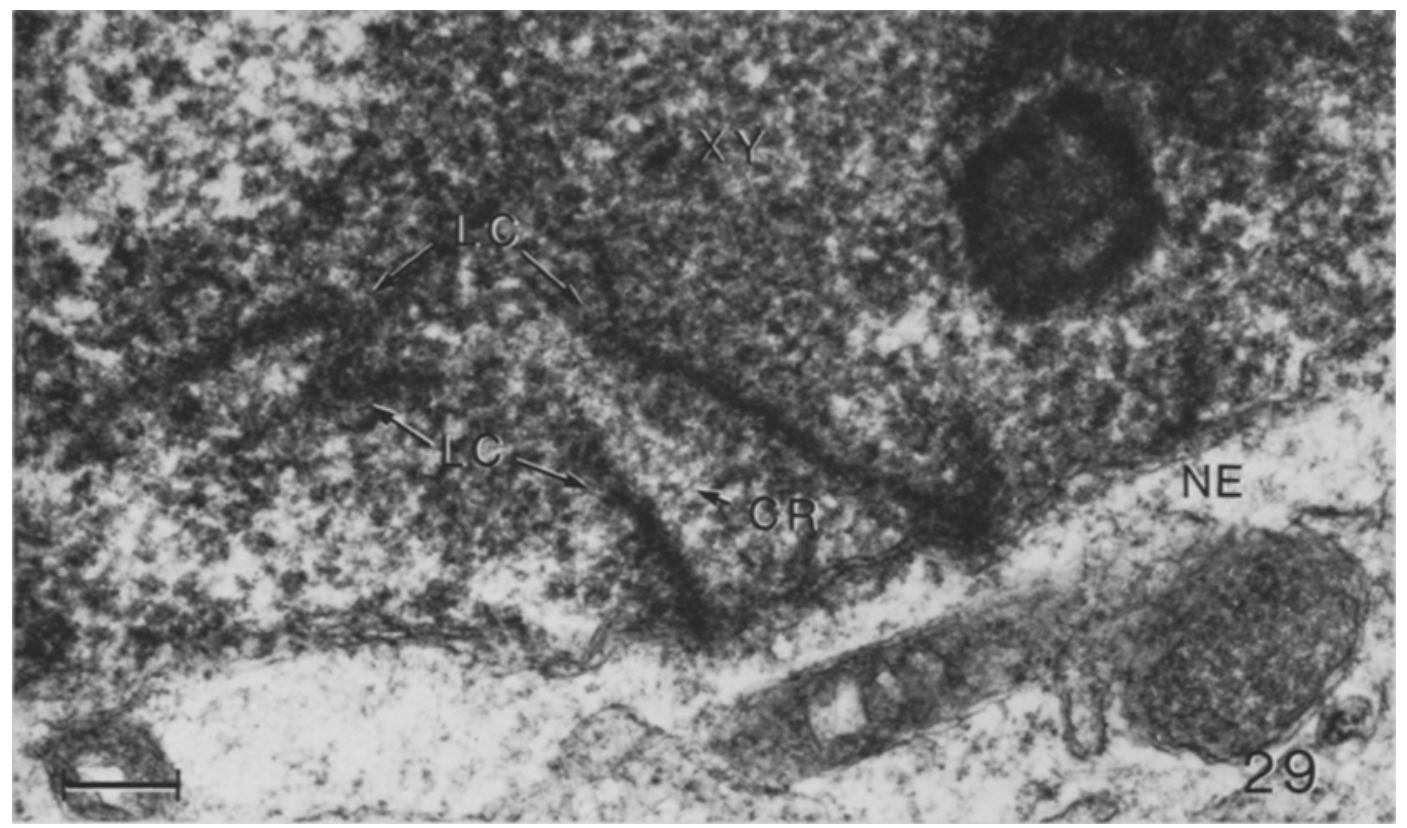

Figure 29. An example of aberrant synaptonemal complex formation as a result of entrapment of homologous telomeric regions by the chromatin of the $\mathrm{XY}$ body (XY). The lateral components (LC) of bivalent 11 (nucleus 21) are attached to the nuclear envelope (NE) about $3000 \dot{A}$ apart and with a central region (CR) attached to only one of the lateral components.

$(\mathrm{Bar}=0.2 \mu \mathrm{m})$

in transcription of ribosomal genes reported to occur during pachytene in man (5l) and mouse (30). The decrease in transcription may result from an inactivation of ribosomal DNA by condensation of the chromatin of the secondary constriciton as suggested by TRES (51).

\subsection{The XY body}

The presence of a small segment of synaptonemal complex between the terminal parts of the $\mathrm{X}$ and $\mathrm{Y}$ chromosomes has previously been described by SOLARI and TRES (48). In agreement with their findings, the present study has revealed distinct synaptonemal complex segments between the $\mathrm{X}$ and $\mathrm{Y}$ chromosomes in the majority of the nuclei analyzed, covering the entire pachytene stage. The $X Y$ bivalents with less distinct synaptonemal complex segments which were found in the present study were not confined to a specific stage in pachytene. The structural modification and shortening of the complex segments during pachytene reported by SOLARI and TRES (48) could thus not be confirmed. It is conceivable that the formation of the synaptonemal complex between the homologous regions of the sex chromosomes during zygotene is influenced by the condensation of the $\mathrm{X}$ and $\mathrm{Y}$ chromosomes. Differences in length of the complex segment as well as in the organization of its constituents may therefore be the result of a variation in the degree of condensation of the sex bivalent at the time of synaptonemal complex formation.

Light microscopical analyses of diplotene and diakinesis bivalents have shown that the short arms of the $X$ and $Y$ chromosomes generally appear to be associated at their telomeres $(8,9,39)$ indicating the presence of a chiasma at this position. Thus it is likely that the synaptonemal complex segments of the $\mathrm{XY}$ body are formed by the short arms of the sex chromosomes. 


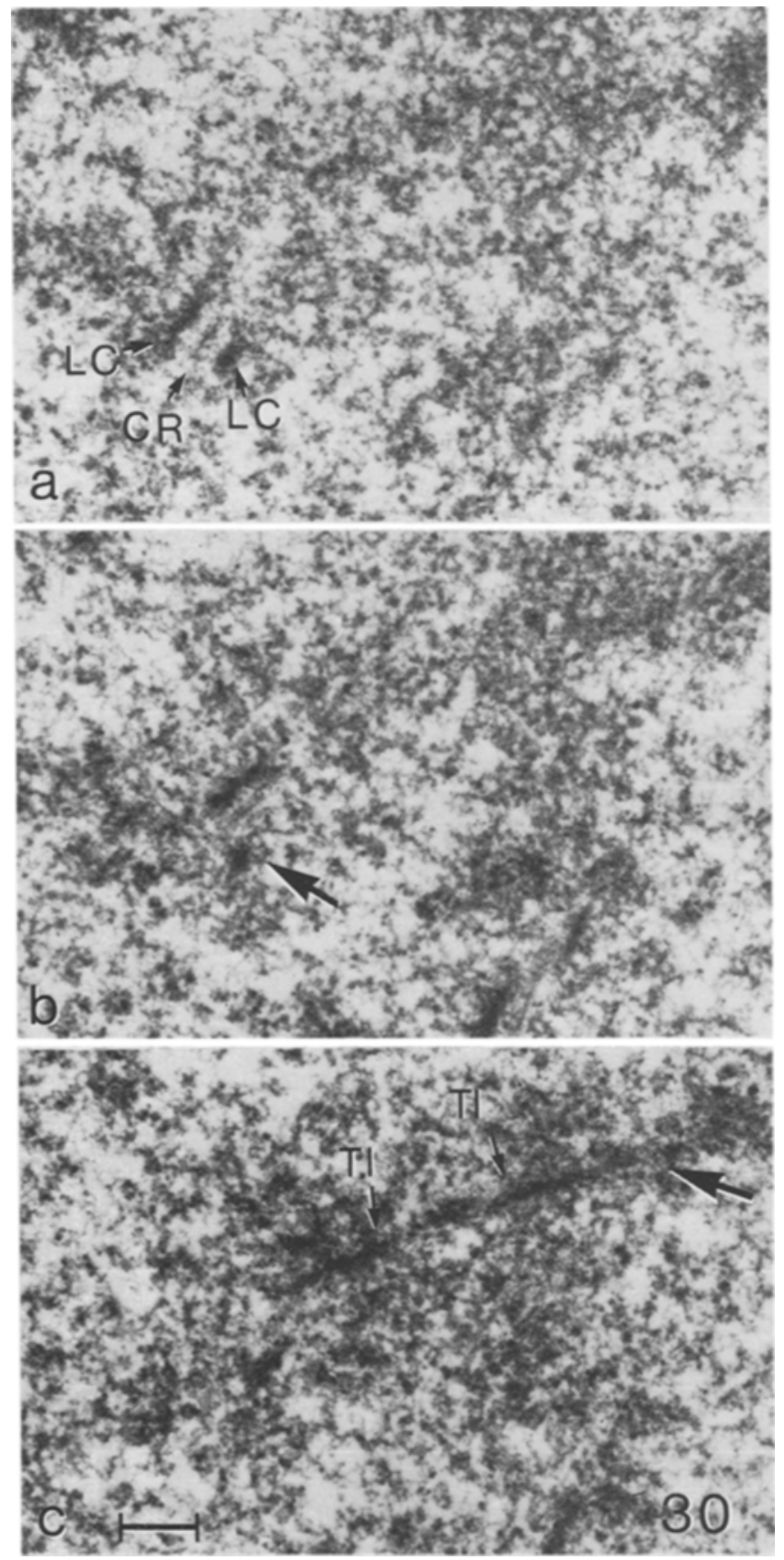

The association of nucleoli with the XY body observed in two nuclei may be incidental as hybridization experiments have failed to detect ribosomal DNA cistrons on the $\mathrm{X}$ and $\mathrm{Y}$
Figure 30. Three consecutive sections through the terminal region of the short arm of bivalent 1 . In Figures $a$ and $b$, two lateral components (LC) are paired with a normal central region (CR), whereas in Figure c, only one lateral component can be recognized. Neither of the ends are attached to the nuclear envelope. It is conceivable that this configuration is the result of a breakage of one of chromosomes 1 (points of breakage denoted by arrows); the fragment being associated telomere-to-telomere (T1) to the other chromosome 1 .

(Bar $=0.2 \mu \mathrm{m})$

chromosomes (12). A similar situation is however reported in the mouse, where nucleoli are associated with the sex chromosomes $(46,30)$ although ribosomal DNA appears to be absent (11). Further experiments are required to elucidate the nature of the sex chromosome/ nucleolus associations.

\subsection{Total length of the autosomal synaptonemal complexes}

Differences in the total length of the synaptonemal complex complement among the nuclei of a single or several individuals are insignificant. The total complement length is also unaffected by the progressive chromatin condensation which occurs during pachytene. These results are in agreement with earlier reports on constancy of total synaptonemal complex length at pachytene in maize (17), Bombyx (40), and Sordaria (53). In Drosophila melanogaster, a decrease in synaptonemal complex length has been described for two chromosome segments during the first half of pachytene and an increase towards the end of pachytene (4). A similar change in total complex length during pachytene is postulated by Moses (37) in Chinese hamster.

The length of a double helix equivalent to the total amount of DNA per $G_{2}$ nucleus is estimated to approximately $4.6 \times 10^{6} \mu \mathrm{m}$ (44). As the mean absolute length of the synaptonemal complex per nucleus in $231 \mu \mathrm{m}, 0.01 \%$ of the total DNA double helix equals the combined lengths of the lateral components in a human pachytene nucleus. Similar calculations are 
available for yeast $(2 \%, 2)$, Neurospora $(0.3 \%$, 16), Drosophila melanogaster $(0.2 \%, 52)$, Bom byx $(0.12 \%, 40)$ Maize $(0.015 \%, 17)$, Lilium (zygotene value, $0.006 \%, 24)$, Chinese hamster $(0.012 \%, 37)$ golden hamster $(0.013 \%, 37)$ and mouse $(0.014 \%, 37)$.

Finally, it should be noted that the mean length of $231 \mu \mathrm{m}$ for the synaptonemal complex complement of the 22 pachytene nuclei is in good agreement with a total length of $241 \mu \mathrm{m}$ for pachytene bivalents as measured on the pachytene idiogram of LUCIANI et al. (32).

\subsection{The pachytene karyotype}

The comparison of the relative synaptonemal complex lengths at pachytene and the relative bivalent lengths at diakinesis (26) has shown that the relative lengths of the individual chromosomes are similar in the two stages. The differences encountered for 13 og the 22 bivalents are small as seen in Figures 25 and 27 but statistical analyses revealed them to be significant. Only bivalents $16,17,19$, and 20 exibit larger differences in relative length. The mechanism underlying this differential contraction is at present not known.

The relative position of the centromere is also very similar in pachytene and diakinesis bivalents (Figures 26 and 27). Only bivalent 5 exibits a pronounced difference in centromere index in the two stages.

These observations demonstrate that differential shortening of bivalents during the meiotic prophase occurs only to a limited extent. It also implies that the cassification of the bivalents on the basis of relative synaptonemal complex lengths and centromere indices only in rare cases is expected to be incorrect (with the exception of the bivalents in the C and D groups as previously mentioned). A good correlation between light and electron microscopical data on relative chromosome lengths and/or centromere indices has also been reported for other organisms $(16,17,24,34)$.

\subsection{Variation in bivalent length and centromere index}

Errors in the determination of section thickness and magnification of micrographs may result in differences of 10 per cent in the absolute length of the synaptonemal complex. Considerable larger differences are encountered when the length of a bivalent is studied in different nuclei. In contrast to this variation the lateral components of the two homologous chromosomes within a single nucleus have the same lengths, i.e., an unpaired lateral component was never observed to extend beyond the central region (with one possible exception, see under Results section 3.7.6). These observations are in agreement with analyses of the synaptonemal complex and its constituents in leptotene, zygotene, and pachytene nuclei reported by HOLM (24), Gillies $(16,17)$, Beyers and Goetsch (2), Zickler (53), Rasmussen (40, 42), Goldstein and MoEns (20), and others.

Whether the differences in relative chiasma frequencies of individual bivalents among different nuclei reported by HULTÉN (26) are related to the differences in synaptonemal complex lenght remains to be analyzed. Strong indication for such a positive correlation between relative synaptonemal complex length and crossing over frequencies has however been reported for other organisms. In Zea mays, GILLIES (17) found an increase in synaptonemal complex length in the presence of an abnormal chromosome 10, a chromosome which is known to promote crossing over. Analogous results have been obtained by MOGENSEN (34) in a comparison of synaptonemal complex length between bivalents from micro- and megasporocytes of Zea mays. The short arm of chromosomes 9 is longer in microsporocytes that in megasporocytes and a comparable increase in crossing over frequency has been reported by RHOADES for the short arm of chromosome 9 in microsporocytes. In man, Hultén (26) was able to show a good correlation between relative length of diakinesis bivalents and relative chiasma frequencies. It should be noted, that the relative bivalent lengths as determined by the lengths of synaptonemal complexes and the relative chiasma frequency do not differ significantly for 12 autosomes (compared with a t-test, $\quad \mathrm{P}>\quad 0.05$ ). The relative chiasma frequencies generally correlate better with the relative lengths of the synaptonemal complexes 


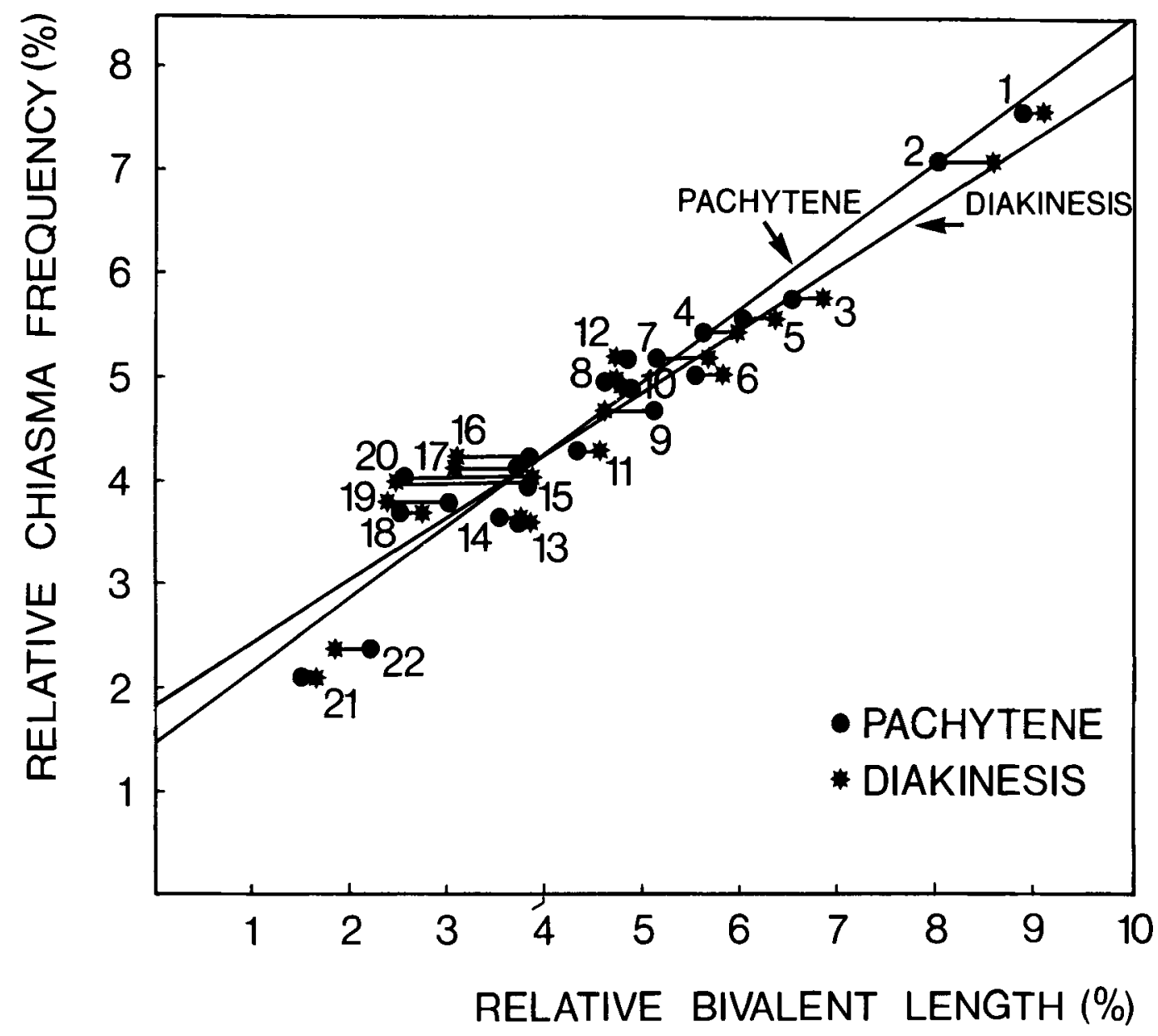

Figure 31. A comparison between the relative chiasma frequency and the relative bivalent length at pachytene and diakinesis. (The data on relative bivalent lengths at diakinesis and the relative chiasma frequencies are from Hultén, 1974, 26). The correlation coefficients are 0.97 and 0.95 respectively. The relative chiasma frequencies correlate better with the relative lengths of synaptonemal complexes than with the relative bivalent lengths at diakinesis.

than with the relative lengths of diakinesis bivalents. This is in particular clear for the bivalents 16, 17, 19, and 20 (Figure 31 ).

\subsection{Concluding remarks}

The present investigation has demonstrated that all pachytene bivalents can be identified or at least allocated unambiguously into one of the main groups on the basis of absolute and relative length of their synaptonemal complex and the position of the centromeric heterochromatin. The number of aberrant syn- aptonemal complexes was insignificant in comparison with the number of bivalents with a normal synaptonemal complex throughout their entire length.

The method used in the present study is thus suitable for detailed analysis of chromosome pairing in nuclei with rearranged chromosome segments such as translocation, inversions, deletions etc. Also the effects of radiation and cytostatica may be analysed in greater detail with the aid of the present method. 


\section{ACKNOWLEDGEMENTS}

We are indebted to professor D. vON WETTSTEIN for his encouragement and many helpful discussions during the course of the work and for his valuable criticisms of the manuscript. We also wish to thank Drs. N.E. SKAKKEBßK and M. HULTÉN for their generous help and advice and for their assistance in obtaining the testicular biopsies. It is a great pleasure to thank JEAN SAGE for her skilled assistance in sectioning the large amount of material used in this study and for photographing several of the series. The outstanding technical assistance of P. Howard (Regional Cytogenetics Laboratory, Birmingham), A. L. PERSSON (Rigshospitalet, Copenhagen), A. Steinholtz, S. Mogensen, and N. RASMUSSEN are gratefully acknowledged. Finally we thank cand. stat. L. SEJERSEN for assistance in the statistical analysis of the results. The work was supported by grant 202-76-1 BIO DK from the Commission of the European Communities.

\section{REFERENCES}

1. Anderson, P. J.: Purification and quantitation of glutaraldehyde and its effects on several enzyme activities in skeletal muscie. J. Histochem. Cytochem. 15, 652-661 (1967)

2. Beyers, B. \& L. Goetsch: Electron microscopic observations on the meiotic karyotype of diploid and tetraploid Saccharomyces cerevisiae. Proc. Nat. Acad. Sci. USA 72, 5056-5060 (1975)

3. Bross, K. \& W. Krone: On the number of ribosomal RNA genes in man. Humangenetik 14 , 137-141 (1972)

4. Carpenter, A. T. C.: Electron microscopy of meiosis in Drosophila melanogaster females. I. Structure, arrangement, and temporal change of the synaptonemal complex in wild-type. Chromosoma (Berl.) 51, 157-182 (1975)

5. Carpenter, A. T. C.: Electron microscopy of meiosis in Drosophila melanogaster. II. The recombination nodule - a recombination associated structure at pachytene? Proc. Nat. Acad. Sci. USA 72, 3186-3189 (1975)

6. CARR, D. H.: Chromosomes and abortion. In $\mathrm{H}$. Harris \& K. Hirschhorn (Eds.) Advances in Human Genetics, vol. 2, chapter 4, p. 201-256
(1970)

7. Caspersson, T., M. hultén, J. Lindesten \& L. ZECH: Identification of chromosome bivalents in human male meiosis by quinacrine mustard fluorescence analysis. Hereditas 67, 147-149 (1971)

8. Chen, A. T. L. \& A. Falek: Centromeres in human meiotic chromosomes. Science 166, 1008 1010(1969)

9. Chen, A. T. L. \& A. Falek: Cytological evidence for the association of the short arms of the $\mathrm{X}$ and $\mathrm{Y}$ chromosomes in the human male. Nature 232, 555-556 (1971)

10. Denver Report 1960: Birth Defects, Orig. Art. Ser. II (2), 12-17. The National Foundation, N. Y. (1966)

11. Elsevier, S. M. \& F. H. RuddLE: Location of genes coding for $18 \mathrm{~S}$ and $28 \mathrm{~S}$ ribosomal RNA within the genome of Mus musculus. Chromosoma (Berl.) 52, 219-228 (1975)

12. Ewans, H. J., R. A. Buckland \& M. L. Pardue: Location of the genes coding for $18 \mathrm{~S}$ and $28 \mathrm{~S}$ ribosomal RNA in the human genome. Chromosoma (Berl.) 48, 405-426 (1974)

13. Ferguson-Smith, M. A.: The sites of nucleolus formation in human pachytene chromosomes. Cytogenetics 3, 124-134 (1964)

14. Gagne, R., C. Laberge \& R. Tanguay: Aspect cytologique et localisation intranucléaire de l'hétérochromatine constitutive des chromosomes C9 chez l'homme. Chromosoma (B erl.) 41, 159-166 (1973)

15. Geraedts, J. P. M. \& P. L. Pearson: Chromosomes in human spermatozoa. In P. L. Pearson \& K. R. Lewis (Eds.) Chromosomes Today, vol. 5, p. 23-31, John Wiley and Sons, New York (1974)

16. GiLliEs, C. B :- Reconstruction of the Neurospora crassa pachytene karyotype from serial sections of synaptonemal complexes. Chromosoma (Berl.) 36, 119-130(1972)

17. Gillies, C. B.: Ultrastructural analysis of maize pachytene karyotypes by three dimensional reconstructions of the synaptonemal complexes. Chromosoma (Berl.) 43, 145-176 (1973)

18. Gillies, C. B.: Synaptonemal complex and chromosome structure. Ann. Rev. Genet. 9, 91109 (1975)

19. Gillies, C. B.: An ultrastructural analysis of chromosomal pairing in maize. Compt. Rend. Trav. Lab. Carlsberg 40, 135-161 (1975)

20. Goldstein, P. \& P. B. Moens: Karyotype analysis of Ascaris lumbricoides var.suum. Chromosoma (Berl.) 58, 101-111 (1976)

21. Gosden, J. R., A. R. Mitchell, R. A. 
Buckland, R. P. Clayton \& H. J. Evans: The location of four human satellite DNAs on human chromosomes. Exptl. Cell Res, 92, 148-158 (1975)

22. Heller, C. G. \& Y. Clermont: Kinetics of the germinal epithelium in man. Recent Prog. Horm. Res. 20, 545-575 (1964)

23. Henderson, A. S., D. Norburton \& K. C. ATwOoD: Location of rRNA in the human chromosome complement. Proc. Nat. Acad. Sci. USA $68,3394-3398(1972)$

24. Holm, P. B.: Three-dimensional reconstruction of chromosome pairing during the zygotene stage of meiosis in Lilium longiflorum (Thunb.) Carlsberg Res. Commun. 42, 103-151 (1977)

25. Hultén, M. \& J. LindSTEN: Cytogenetic aspects of human male meiosís. In $\mathrm{H}$. Harris \& $\mathrm{K}$. Hirschhorn (Eds.), Advances in Human Genetics, vol. 4, chapter 5, p. 327-387 (1973)

26. Hulten, M.: Chiasma distribution at diakinesis in the normal human male. Hereditas $76,55-78$ (1974)

27. Hulten, M., E. A. de Weerd-Kastelejn, D. Bootsma, A. J. Solari, N. E. SKaKKeb \&K \& G. SWANBECK: Normal chiasma formation in a male with xeroderma pigmentosum. Hereditas 78,117 124 (1974)

28. Hulté, M., A. J. Solari \& N. E. SKaKKebak: Abnormal synaptonemal complex in an oligochiasmatic man with spermatogenic arrest. Hereditas 78, 105-116 (1974)

29. Hungerford, D. A., F. T. Ashton, G. B. Balaban, G. U. LaBadie, L. R. Messatzzia, G. Haller \& A. E. Miller: The C-group pachytene bivalent with a locus characteristic for parachromosomally situated particulate bodies (parameres): A provisional map in human males. Proc. Nat. Acad. Sci. USA 69, 2165-2168 (1972)

30. Kierszenbaum, A. L. \& L. L. Tres: Nucleolar and perichromosomal RNA synthesis during meiotic prophase in the mouse testis. J. Cell Biol. 60, 39-53 (1974)

31. Leblond, C. P. \& Y. Clermont: Definitions of the stages of the cycle of the seminiferous epithelium in the rat. Ann. N.Y. Acad. Sci. 55, 548-573 (1952)

32. Luciani, J. M., M. R. Morazzani \& A. Stahl: Identification of pachytene bivalents in human male meiosis using G-banding technique. Chromosoma (Berl.) 52, 275-282 (1975)

33. MoEns, P. B.: Quantitative electron microscopy of chromosome organization at meiotic prophase. Cold Spr. Harb. Symp. Quant. Biol. 38, 99-107 (1973)

34. Mogensen, L. L.: Ultrastructural analysis of female pachynema and the relationship of syn- aptonemal complex length to crossing over in Zea mays. Carlsberg Res. Commun. 42, in press (1977)

35. Moses, M. J.: Synaptinemal complex. Ann. Rev. Genet. 2, 363-412 (1968)

36. Moses, M. J., S. J. Counce \& D. F. Paulson: Synaptonemal complex complement of man in spreads of spermatocytes, with details of the sex chromosome pair. Science 187, 363-365 (1975)

37. Moses, M. J., G. H. Slatton, T. H. Gambling \& C. F. Starmer: Synaptonemal complex caryotyping in spermatocytes of the chinese hamster (Cricetulus griceus). Chromosoma (Berl.) 60, 345-375 (1977)

38. Paris Conference (1971): Standardization in human cytogenetics. Cytogenetics 11, 313-362 (1972)

39. Pearson, P. L. \& M. Bobrow: Definitive evidence for the short arm of the $\mathrm{Y}$ chromosome associating with the $\mathrm{X}$ chromosome during meiosis in the human male. Nature 226, 959-961 (1970)

40. Rasmussen, S. W: The meiotic prophase in Bombyx mori females analyzed by three dimensional reconstructions of synaptonemal complexes. Chromosoma (Berl.) 54, 245-293 (1976)

41. Rasmussen, S. W.: The transformation of the synaptonemal complex into the "elimination chromatin" in Bombyx mori oocytes. Chromosoma (Berl.) 60, 205-221 (1977)

42. Rasmussen, $S$. W.: Chromosome pairing in triploid females of Bombyx mori analyzed by three dimensional reconstructions of synaptonemal complexes. Carlsberg Res. Commun. 42, 163-197 (1977)

43. Reynolds, E. S.: The use of lead citrate at high $\mathrm{pH}$ as an electron opaque stain in electron microscopy. J. Cell Biol. 17, 298-311 (1963)

44. Saunders, G. F., S. Shirakawa, P. P. Saunders, F. E. Arrighi \& T. C. Hsu: Populations of repeated DNA sequences in the human genome. J. Mol. Biol. 63, 323-334 (1972)

45. Sкаккевек, N. E.: Kvantitative studier af det germinative epithel i den humane testis. Thesis (in danish with english summary). FADL's Forlag, København, Denmark (1974)

46. SOLARI, A. J.: The evolution of the ultrastructure of the sex chromosomes (sex vesicle) during meiotic prophase in mouse spermatocytes. J. Ultrastruct. Res. 27, 289-305 (1969)

47. Solari, A. J.: The behaviour of chromosomal axes during diplotene in mouse spermatocytes. Chromosoma (Berl.) 31, 217-230 (1970)

48. Solari, A. J. \& L. L. Tres: The three- 
dimensional reconstruction of the $\mathrm{XY}$ chromosomal pair in human spermatocytes. J. Cell Biol. 45, 43-53(1970)

49. Sotelo, J. R., R. B. Garcia \& R. Wettstein: Serial sectioning study of some meiotic stages in Scaptericus borelli (Grylloidea). Chromosoma (Berl.) 42, 307-333 (1973)

50. SPuRr, A. R.: A low-viscosity epoxy resin embedding medium for electron microscopy. J. Ultrastruct. Res. 26, 31-43(1969)

51. TRES, L. L.: Nucleolar RNA synthesis of meiotic prophase spermatocytes in the human testis. Chromosoma (Berl.) 53, 141-151 (1975)

52. Westergaard, M. \& D. von Wettstein: The synaptinemal complex. Ann. Rev. Genet. 6, 71110 (1972)

53. ZiCKLER, D.: Development of the synaptonemal complex and the "recombination nodule" during meiotic prophase in the seven different bivalents of the fungus Sordaria macrospora Auersw. Chromosoma (Berl.) 61, 289.316 (1977) 